Florida International University FIU Digital Commons

\title{
The Path of Least Resistance: An Advanced Index Alternative to the Cultural Distance Index for Measuring International Expansion
}

Dale Alan DeJong

ddejong@fiu.edu

DOI: $10.25148 /$ etd.FIDC001911

Follow this and additional works at: https://digitalcommons.fiu.edu/etd

Part of the Business Administration, Management, and Operations Commons

\section{Recommended Citation}

DeJong, Dale Alan, "The Path of Least Resistance: An Advanced Index Alternative to the Cultural Distance Index for Measuring International Expansion" (2017). FIU Electronic Theses and Dissertations. 3483.

https://digitalcommons.fiu.edu/etd/3483 


\section{FLORIDA INTERNATIONAL UNIVERSITY}

Miami, Florida

\section{THE PATH OF LEAST RESISTANCE: AN ADVANCED INDEX ALTERNATIVE TO THE CULTURAL DISTANCE INDEX FOR MEASURING INTERNATIONAL EXPANSION}

A dissertation submitted in partial fulfillment of

the requirements for the degree of

DOCTOR OF PHILOSOPHY

in

BUISINESS ADMINISTRATION

by

Dale Alan DeJong

2017 
To: Dean Joanne Li

College of Business

This dissertation, written by Dale Alan DeJong, and entitled The Path of Least Resistance: An Advanced Index Alternative to the Cultural Distance Index for Measuring International Expansion, having been approved in respect to style and intellectual content, is referred to you for judgment.

We have read this dissertation and recommend that it be approved.

$\begin{array}{r}\text { Modesto A. Maidique } \\ \hline \text { Ochieng F. Walumbwa } \\ \hline \text { George S. Dulikravich } \\ \hline \text { Mido Chang } \\ \hline \text { Garen Paul, Major Professor }\end{array}$

Date of Defense: June 22, 2017

The dissertation of Dale Alan DeJong is approved.

Dean Joanne Li College of Business

Andrés G. Gil Vice President for Research and Economic Development and Dean of the University Graduate School

Florida International University, 2017 


\section{ABSTRACT OF THE DISSERTATION}

THE PATH OF LEAST RESISTANCE: AN ADVANCED INDEX ALTERNATIVE TO THE CULTURAL DISTANCE INDEX FOR MEASURING INTERNATIONAL EXPANSION

by

\section{Dale Alan DeJong}

Florida International University, 2017

Miami, Florida

\section{Professor Karen Paul, Major Professor}

In response to a call for more advanced and more inclusive models for measuring difficulty of international expansion, the resistance index (RI) was created and is advanced in this paper. The RI includes several factors that contribute (detract) to the success (failure) of firms regarding cross border expansion. The RI features variables that represent country specific advantages (CSA), firm specific advantages (FSA), and government specific advantages (GSA). These three areas are represented by a diverse set of data obtained from such widely recognized agencies as the World Bank and Thomson Reuters. Taking data from different sources, may render better predictability for firms than using the popular cultural distance index. Therefore, it is proposed that the RI may be a more relevant tool for firms to use when they are considering international expansion into a particular country, or for researchers to employ in undertaking success or failure in international expansion. 


\section{TABLE OF CONTENTS}

CHAPTER

PAGE

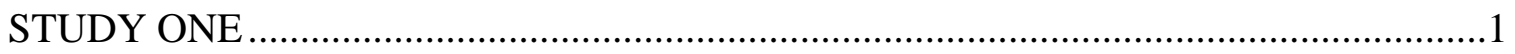

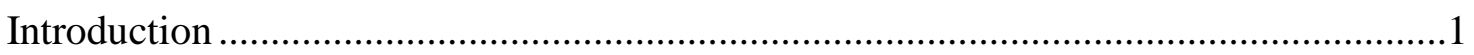

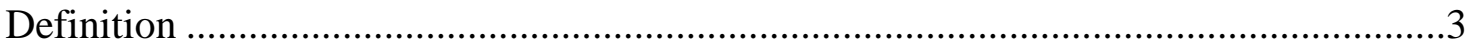

Explanation of the Resistance Index .........................................................................5

Explanation and Justification for Resistance Index ................................................8

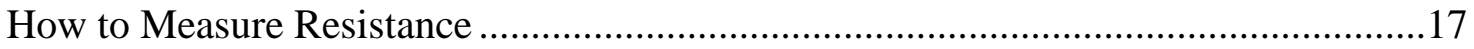

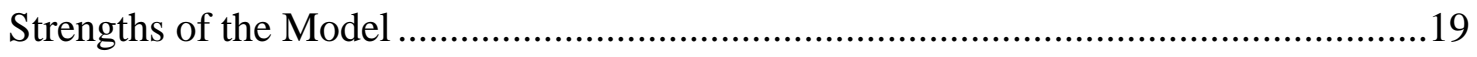

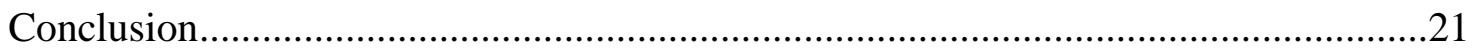

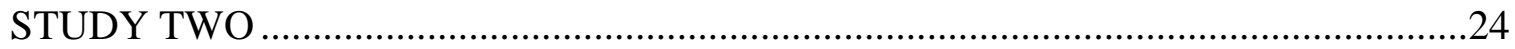

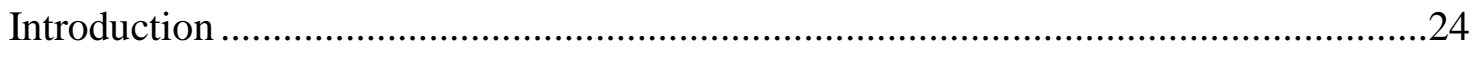

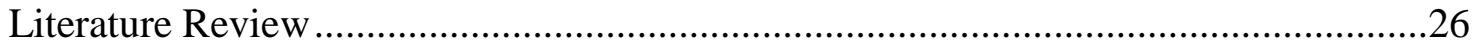

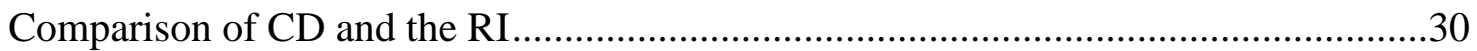

Hidden Assumptions, Conceptual Properties, and Methodological Issues ...................37

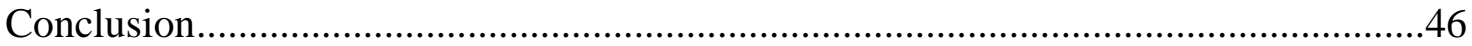

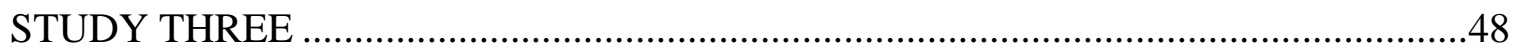

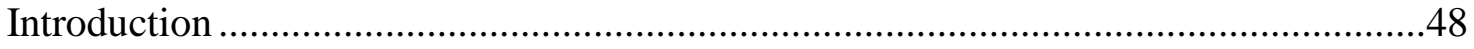

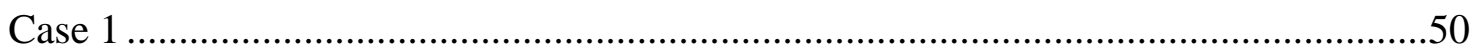

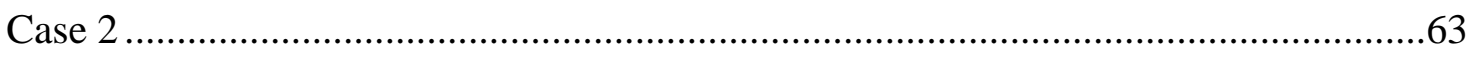

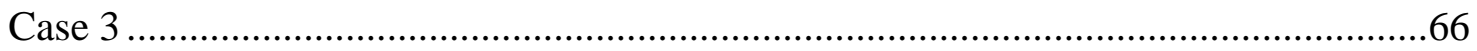

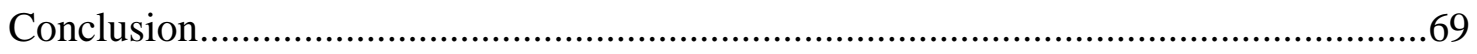

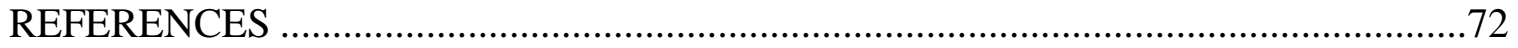

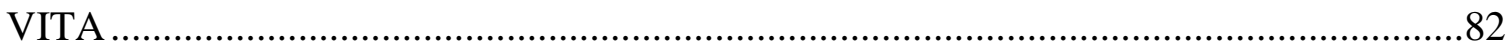




\section{LIST OF TABLES}

TABLE

PAGE

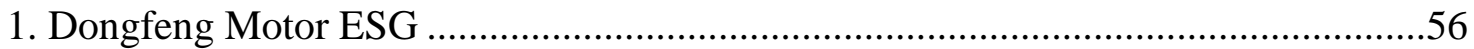

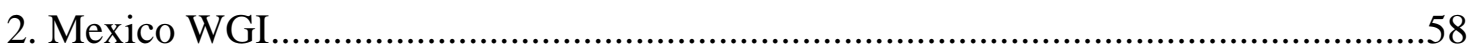

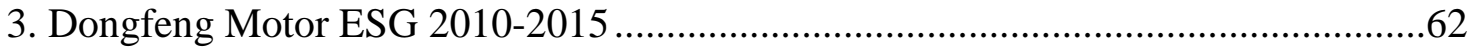

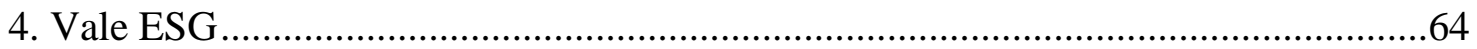

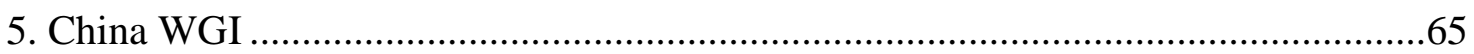

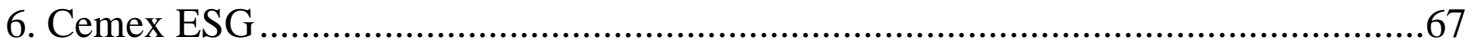

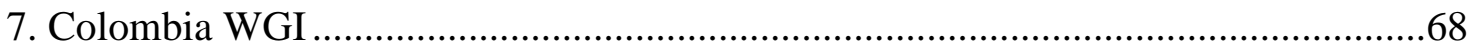




\section{STUDY ONE}

\section{Introduction}

The path of least resistance is the physical or metaphorical pathway that provides the least resistance to forward motion by a given object or entity, among a set of alternative paths. The concept is often used to describe why an object or entity takes a given path. The Resistance Index (RI) is one step in this direction. This index can help firms and managers assess situations surrounding international expansion possibilities by looking at the areas of concern (factors giving the highest contribution to the resistance), taking action to reduce or alleviate these problem areas, thereby pursuing the path of least resistance. This tool will be especially helpful to practitioners who look at transaction costs as a reason for international expansion.

The RI incorporates several variables (discussed later) from three different areas of concern: country specific advantages (CSA), firm specific advantages (FSA), and government specific advantages (GSA). Many scholars have suggested a need for a more advanced and comprehensive model (e.g., Shenkar, 2001, 2012; Tung \& Verbeke, 2010; Zaheer, Schomaker, \& Nachum, 2012) than the cultural distance model and the RI is in answer to that plea. Brouthers \& Brouthers (2000) state “Our results provide initial support for using a model which includes institutional and cultural variables, as well as transaction cost variables to predict firms' choices between acquisitions and greenfield start-ups in international expansion” (p96).

Zaheer, Schomaker, and Nachum (2012) state, "Following the adage that 'the best tool is the one that fits the job', we suggest that research into a particular process or decision may sometimes be best informed by theory and measures from fields other than 
international business itself. This kind of interdisciplinary approach provides new and potentially more insightful ways to parse the elements of societal difference and bring greater rigor to the constructs and measures of distance” (p25). Luo and Shenkar’s (2011) theoretical paper proposing a cultural friction model, based on the mechanical engineering friction model, is an excellent example of this interdisciplinary cross reference. The RI is also based on the engineering model of friction with a considerably different tack in how it is used. While Luo and Shenkar state "Although it is beyond the scope of the present paper to develop a full-fledge framework" (p10) this paper constructs a full-fledged framework for RI.

Both the cultural friction model (Luo \& Shenkar, 2011) and the RI are in response to the cultural distance index (CD) from Kogut and Singh (1988). The CD model has enjoyed great success over the years in part due to its simplicity. As stated by Ambos and Håkanson (2014), "The popularity of the index was primarily due to the ease of its computation” (p2).

Ever since Hofstede published “Culture's Consequences” (1980), the academic and practitioner worlds have been turned upside down. In this seminal work Hofstede categorized culture with four cultural dimensions: uncertainty avoidance, individualism/collectivism, masculinity/femininity, and power distance. The world of international business has been debating the effectiveness of such measures ever since. Kogut and Singh (1988) created a formula to measure the differences in the Hofstede numbers between countries called the Cultural Distance (CD) index and the commentaries for and against this index have raged subsequently. 
In 2001 Shenkar wrote his award winning paper called “Cultural distance revisited:

Towards a more rigorous conceptualization and measurement of cultural differences” in which he critiques the shortcomings of the cultural distance model. One of Shenkar's most critical statements is, "The appeal of the CD construct is, unfortunately, illusory. It masks serious problems in conceptualization and measurement, from unsupported hidden assumptions to questionable methodological properties, undermining the validity of the construct and challenging its theoretical role and application.” However, even after such criticism the CD model continues to enjoy wide success to this date.

In response Luo and Shenkar (2011) published their cultural friction model. The cultural friction model is not a finished product as the author's state. The main point of the paper was to inspire someone to come up with a functioning model that would incorporate more variables than just Hofstede's dimensions as used in the CD index. To this end this paper conceives of the RI. The RI is more complex than the CD index, however, it is still computationally easier to use than the cultural friction model.

Definition

There has been considerable debate concerning the metaphor "distance" and its relevance to different business situations. Johanson and Vahlne (1977) use psychic distance, Berry, Guillen and Zhou (2010) use nine different measures of distance: economic, financial, political, administrative, cultural, demographic, knowledge, global connectedness, and geographic. The question becomes this: can the term “distance” convey the varied meanings of the different variables with which it is associated? 
Shenkar, Luo, and Yeheskel (2008) have suggested that,“Substituting 'friction' for 'distance' denotes shifting the emphasis from abstract differences toward contact between specific entities, onto their partisan concerns” (p 911). Unfortunately, not many people have taken this approach and the "distance" metaphor is still widely used. Yet, though the idea of "friction" is sound the metaphor is a problem. "Friction" is not a commonly used term in business or with the general public. The term "resistance" is a term that may accomplish shifting the emphasis away from "distance” and still be acceptable.

"Resistance" is more commonly used in business and especially in finance when referring to resistance at certain levels of stock price.

According to the Oxford English Dictionary (OED)(“resistance,”2017):

resistance, $n$. is

1a. The action of resisting, opposing, or withstanding someone or something

2a. The impeding or stopping effect exerted on an object or substance by another, or by a force: the susceptibility to such an effect on the part of an object or structure.

When investigating international expansion, managers have to look at what will resist, oppose or impede the company's entrance into the foreign market. The OED continues with examples of the use of the term "resistance."

Phrases

P1b. line of least resistance $n$.

the easiest route, method, course of action, etc. (also path, etc., of least resistance). 
Again, managers want to know the easiest route, method, or course of action the company might take to make the venture successful. From a transaction cost viewpoint, this means minimizing costs and maximizing profits.

The OED also uses the stock market as an example of the use of resistance:

\section{Compounds}

C1a. Relating to or involving resistance to force or pressure. resistance-attribute $\mathrm{n}$.

C4resistance level n. Stock Market an upper price level for a security or commodity that is repeatedly reached but not exceeded due to market resistance:

The dictionary then goes on to give examples of how resistance is used with other words. Here are some of the examples given:

C5. With preceding word denoting an action or effect that is resisted, as abrasion resistance, crease resistance, shrink resistance, skid resistance, etc.: or one denoting a state or substance that is resisted, as drug resistance, flame resistance, etc.

Thus, resistance is very apropos for a business model yielding the degree of difficulty a firm might encounter concerning a specific cross-border expansion.

Explanation of the Resistance Index

The RI was inspired by the friction model of Luo and Shenker (2011) as mentioned before (shown below). 


$$
F=\left[e^{V(1-G) *} \frac{C D}{10}\right]\left[\frac{\sum L_{i}}{N_{L}} * \frac{\sum S_{i}}{N_{S}}\right]\left[\frac{1}{1+\sum_{i=1}^{N_{L}} t_{i} l_{i}}\right]
$$

This is a very impressive looking model but it is not easy to use and some of the variables are difficult, if not impossible, to quantify.

However, unlike the Luo and Shenkar model, the RI has maintained a simpler version of the engineering friction model (Avallone, Baumeister, and Sadegh, 2007). The original friction model is:

$$
\mathrm{F}=\mathrm{f} \mathrm{N} \text {. }
$$

When the RI morphs into the final version it is quite different, but in practice it remains as simple as the original friction model shown above. It is important to understand the components that make up the original friction model. The symbol $\mathrm{f}$ is the load, or what we are looking to move. This load can be made up of many elements or a single element. Therefore, if we envision a box with several different items in it, like a can of paint, a ladder, paint brushes, and so forth, they would all together constitute the load. $\mathrm{N}$ is the surface over which the load is to be moved. If we want to move our box of painting supplies across the driveway and into the garage, it would depend on how smooth or rough the driveway is as to how difficult the task will be. The F is not friction, so to speak, but is the force necessary to break the load loose so it will travel over the driveway. The friction is the resistance to the movement of the load over the surface and $\mathrm{F}$ is the necessary force needed to accomplish this task. 
To continue the analogy into the business realm, suppose the box contains the CSA that a firm is confronted with when trying to go abroad. The surface area's roughness or smoothness is dependent on the GSA or the governmental practices that make it easy or difficult for a firm to expand into the host country. This is represented by the World Governance Indicators (WGI). If we were to stop here, we could see what force would be necessary to overcome these obstacles and this would certainly be helpful. However, we would be forgetting an ingredient that some researchers, like Harzing and Christensen (2004), feel is paramount to the success of any firm's international venture, the people in the firm. Since it is difficult to use individuals we can use what the individuals do and accomplish within the firm as a proxy for the thoughts and actions of the employees and managers in the firm. This is where Thomson Reuters' Asset 4 ESG is used as a representation of how well the firm is prepared for an international expansion. Asset 4 ESG is a measure of a firm's corporate responsibility and sustainability.

There is a third component that can be added to the equation showing friction and that is called a "lubricant". Lubricants help to ease the friction between the load and the surface. The better the lubricant, the easier the load will move, and less force will be required to move the load. If the lubricant is of poor quality, the less help it will be in reducing the friction, and thus it will create the need for greater force to move the load. Now, the question becomes, how do we apply this concept to ESG? If the board of directors is nationally diversified, it should be easier to expand internationally. The same goes for the other 17 subcategories such as workforce /diversity and opportunity, which gives the firm experience in dealing with a diverse group of employees, which is beneficial in 
expanding internationally, where they will be confronted with different work groups. So the better the ESG numbers for a firm the better prepared the firm and the less difficult for the firm to expand internationally. This lubricant is denoted as the FSA in the model as it constitutes a firm specific advantage.

\section{Explanation and Justification for Resistance Index}

As shown, the RI is based on three major components: FSA, CSA \& GSA. When looking at each component of the model, the load factor, $\mathrm{f}$, is considered CSA, the surface, $\mathrm{N}$, is considered GSA and FSA is considered the lubricant. The RI is shown below.

$$
\begin{array}{r}
R=A *\left[1+\left(1-\frac{C O_{j i}}{10}\right)\right]\left[1+\left(\frac{T}{970}\right)^{k}\right]\left[1+\left(\frac{\varepsilon}{20,038}\right)+\left(\frac{G D}{20,038}\right)^{l}\right] \\
{\left[1+\left(\frac{\sum_{i=1}^{5} E_{i}}{5}\right)^{m}\right]\left[1+\left\{1-\left(\frac{\sum_{j=1}^{G_{S}=6}(3.5+\Delta S)_{j}}{7 * G_{S}}\right)^{n}\right\}\right]\left[1-0.999\left(\frac{\sum_{k=1}^{k=18} P_{k}}{1800}\right)^{o}\right]}
\end{array}
$$

Here,

$\mathrm{R}=$ resistance

$\mathrm{A}=$ arbitrary positive real number (a scale factor)

$C O_{j i}=\sum_{Q=1}^{10}\left\{\min \left(Q_{q i}, Q_{q i}\right) * T_{q}\right\}$ Cultural overlap model (Maseland, 2011)

$0.5<\mathrm{T}<697.0 \quad$ number of days to start a business

$-2.5<\Delta \mathrm{Si}<2.5 \quad$ surface smoothness (WGI)

$G_{S} \quad$ government variables

$0<\mathrm{GD}<20,038 \quad$ geographic distance

$\mathrm{P} \quad$ preparedness of a company (ESG)

$\mathrm{P}_{\max }=18 * 100=1800$ (maximum possible preparedness of a company) 


$$
\begin{aligned}
& P=\sum_{j=1}^{j=18} P_{j} \quad \text { Here, each of the } 18 \text { values of } \mathrm{P}_{\mathrm{j}} \text { can vary between } 0.0 \text { and } 100 . \\
& E_{1}=\left(C_{5}+C_{9}+C_{10}\right) / 300 \quad \text { entry for export/import } \\
& E_{2}=\left(C_{9}+C_{10}\right) / 200 \quad \text { entry for licensing } \\
& E_{3}=\left(C_{1}+C_{5}+C_{6}+C_{7}+C_{9}+C_{10}\right) / 600 \quad \text { entry for joint venture } \\
& E_{4}=\left(C_{1}+C_{2}+C_{3}+C_{4}+C_{5}+C_{6}+C_{10}\right) / 700 \quad \text { entry for greenfield } \\
& E_{5}=\left(C_{1}+C_{4}+C_{5}+C_{6}+C_{7}+C_{8}+C_{9}+C_{10}\right) / 800 \text { entry for mergers/acquisition }
\end{aligned}
$$

$1.0<\mathrm{k}<4.0 \quad$ number of days to start a business exponent

$1.0<1<4.0 \quad$ geographic distance exponent

$1.0<\mathrm{m}<4.0 \quad$ entry mode exponent

$1.0<\mathrm{n}<4.0 \quad$ government exponent

$1.0<0<4.0 \quad$ preparedness of the company exponent

The first section of the model becomes:

$$
\begin{aligned}
R=A *\left[1+\left(1-\frac{C O_{j i}}{10}\right)\right] & {\left[1+\left(\frac{T}{970}\right)^{k}\right]\left[1+\left(\frac{\varepsilon}{20,038}\right)+\left(\frac{G D}{20,038}\right)^{l}\right] } \\
& {\left[1+\left(\frac{\sum_{i=1}^{5} E_{i}}{5}\right)^{m}\right] }
\end{aligned}
$$

This section represents the CSA factor in the model which consists of the cultural overlap model (CO), days to start a business (T), geographic distance (GD), and entry mode (E). The A term is a scale factor so users of the index can create a range that is most suitable for their research. 
$\mathrm{CO}$, the second term in this section, comes from the cultural overlap model (Maseland, 2011). The cultural overlap model employs the concept of commonalities instead of the concept of differences used by the cultural distance model. As stated by Maseland (2011)

Rather than distance to a cultural means, what matters to firms is what segment of the population in a country has the same values as the firm. We construct an overlap measure on the basis of a set of values from the WVS. We show that it has significant effects on MNE location decisions, while upon inclusion of this variable, cultural distance has no significant effects. We conclude that cultural overlap is a theoretically and empirically more relevant conceptualization of cultural differences than cultural distance. (p.1)

The more two cultures have in common, the easier it will be for international business to expand from one culture to the other. Therefore it is postulated:

Proposition 1. The more two countries have in common culturally (higher CO number) the lower the resistance to international expansion and thus a lower resistance number.

The third term is “days to start a business”. This variable is from World Bank’s World Development Indicators (WDI). The time required to start a business (days) gives the number of days required to complete the process, do the legal paper work etc., to start a business in each of the over 200 countries covered in the WGI database. The number of days to start a business is based on the fastest method possible. That means, if the firm can pay extra to have the process expedited, that number of days is used in the database. This is the fastest legally possible way to start a business for each of the economies covered.

If it takes an abnormally long period of time to start a business in a certain country, the firm may choose to not to invest in that country. Thus: 
Proposition 2. The greater the length of time necessary to start a business, the higher the resistance factor.

The fourth part of the CSA section in the resistance index is geographic distance (GD). The GD is the distance between capital cities of countries. This variable is used due to research results from several different sources, such as Rugman and Verbeke (2008), who state that "Service quality can therefore also be expected to vary across geographic space” (p.399). While others have also suggested geographic distance should be considered (e.g.Sarkissian \& Schill, 2004; Dodd, Frijns, \& Gilbert, 2015), others, like Aybar and Ficici (2009), have stated "there is ample evidence suggesting that geographic distance raises the cost of transferring knowledge and technology, and dramatically reduces the effectiveness of knowledge-sharing (e.g., Almeida \& Kogut, 1999; Branstetter, 2001; Keller, 2002; Storper \& Venables, 2004)” (p.1321). Therefore, it is proposed:

Proposition 3. The greater the geographic distance between two countries, the greater the resistance.

The fifth factor is entry mode. The RI uses five types of entry mode: licensing, exporting, joint venture, greenfield, and acquisition. Each entry mode is weighted differently based on the difficulty and shown by $E_{1}$ through $E_{5}$. For example, to do licensing is a matter of contracts between two parties. This is not difficult, but an acquisition is more difficult because you have an equity investment, meshing of personnel, and cultural differences 
that must be taken into consideration (Buono \& Bowditch, 1989; Elsass \& Veiga, 1994; Very, Lubatkin, \& Calori, 1996). Thus, it is postulated:

Proposition 4a. Resistance will be the highest for merger and acquisition entry mode.

Proposition 4b. Resistance will be lower for greenfield entry mode than for merger and acquisition entry mode.

Proposition 4c. Resistance will be lower for joint venture entry mode than for greenfield entry mode.

Proposition 4d. Resistance will be lower for export entry mode than for joint venture entry mode.

Proposition 4e. Resistance will be lower for licensing entry mode than for export entry mode.

The second part of the model follows:

$$
\left[1+\left\{1-\left(\frac{\sum_{j=1}^{G_{S}=6}(3.5+\Delta S)_{j}}{7 * G_{S}}\right)^{n}\right\}\right]
$$

This represents the GSA factor in the model, which consists of six factors obtained from the World Governance Indicators (WGI). These six factors are: Voice and Accountability, Political Stability and Absence of Violence, Government Effectiveness, Regulatory Quality, Rule of Law, and Control of Corruption. These six factors are important components of the RI according to Bandyopadhyay, Roy, \& Liu, (2015). They state that corrupt countries “are characterized by burdensome regulations, which are 
exploited by dishonest officials to extract bribes from traders, thereby driving up the costs of trade” (p11). Also, Nunn (2007) says "contract enforcement explains more of the global pattern of trade than countries' endowments of capital and skilled labor combined" (p570). Rao, Pearce, \& Xin (2005) added the importance of governments in the relationship of managers, their decision making, and the trust developed by them for doing business in a specific country, stating:

Governments with a weak rule of law, high levels of graft and low levels of accountability create uncertainty and undermine the development of trust throughout society, reflected in working organizational relationships. Not only are citizens cautious about engaging with strangers in the public sphere in these opaque environments but also even trust in close business associates is compromised (p116).

As can be seen here, the government plays a vital role in decision making for firms. A firm is more apt to do business in a country whose government is more stable and less corrupt. Thefore:

Proposition 5. Resistance will be higher, the lower the Voice and Accountability.

Proposition 6. Resistance will be higher, the lower the Political Stability and Absence of Violence.

Proposition 7. Resistance will be higher, the lower the Government Effectiveness.

Proposition 8. Resistance will be higher, the lower the Regulatory Quality.

Proposition 9. Resistance will be higher, the lower the Rule of Law.

Proposition 10. Resistance will be higher, the lower the Control of Corruption. 
The last portion of the model is:

$$
\left[1-0.999\left(\frac{\sum_{k=1}^{k=18} P_{k}}{1800}\right)^{o}\right]
$$

This section of the RI model represents the FSA factor and is called firm preparedness. Firm preparedness consists of 18 subcategories contained in the Asset 4 ESG database. The Asset 4 ESG database is broken down into four main categories; governance, economic, environment, and social which are further broken down into 18 subcategories: Board Functions, Board Structure, Compensation Policy, Integration/Vision and Strategy, Shareholder Rights, Margins/Performance, Profitability/Shareholder Loyalty, Revenue/Client Loyalty, Emission Reduction, Product Innovation, Resource Reduction, Customer/Product Responsibility, Society/Community, Society/Human Rights, Workforce/Diversity and Opportunity, Workforce/Employment Quality, Workforce/Health \& Safety, and Workforce/Training and Development. Black, Mendenhall, \& Oddou (1991) state “Cross-cultural training enables the individual to learn both content and skills that will facilitate effective cross-cultural interaction by reducing misunderstandings and inappropriate behaviors” (p 120). Johnson, Lenartowicz, \& Apud also state "the inability of firms and their managers to adjust to the demands of the international business environment has been advanced as a primary cause of international business failures (Tung, 1982; Doremus et al., 1998; Ricks, 1999; Apud et al., 2003)” (p525). Therefore it is proposed:

Proposition 11. The lower the firm preparedness, the greater the resistance. 
As with all of the models there remains the question regarding what variables to use. The unique advantage the RI has is that it can be used with different variables by simply following the format set up for all variables in the model.

A closer look at the model reveals that all parts produce numbers between 0 and 1 . This makes all of the parts comparable on the same scale. In fact, a score of 0 , for some variables, means that the variable is very good and does not contribute to the resistance, so it needs to remain in the model to show this effect. However, because this is a multiplicative model, if any of the components equal 0 then the entire model equals 0 and is worthless. The $1+$ term turns all of the components into a scale from 1 to 2 .

The advantage of the resistance index is that any variable can be eliminated and the index still functions. Alternatively, another variable can be added just by making sure that the variable is set to a 0 to 1 scale. For example, let's say we want to add language differences. If we have a quantified scale of differences, we simply set the number over the max number possible in the set and we have a 0 to 1 scale. Then simply add 1 and now the variable fits into the model with the same weight as each of the other variables. What about weighting variables? Researchers and practitioners may feel that a particular variable should be considered more than the other variables. The RI is flexible enough to accommodate this in two ways. You can weigh the variable itself. For example, if you feel the corruption variable should be given greater weight you can simply multiply it by the factor you feel is appropriate. The second way you can weigh variables is by grouping. For example, if you believe the GSA variable as a whole should be given 
greater weight than the other variables you can multiply the group by a factor of your choosing.

Another aspect of the RI is that you can give different characteristics to each variable, as connoted by the exponents of the model. If you believe the variable takes a certain shape (e.g. if a variable increases exponentially), then you can give it an exponent to show that movement. For example Azman-Saini, Law, \& Ahmad (2010) developed a model to show that FDI "kicks in” only after a certain threshold in financial markets is reached. This may be an important factor for larger MNCs, so they may want to incorporate this model into the RI. This can be done in the RI on an individual level (not shown in the model) or by group level (shown in the model).

Researchers as well as practitioners may have a model they believe best suits a certain area of consideration in international expansion. For example Berry, Guillen and Zhou (2010) have an equation for measuring political distance. Just as the cultural overlap model was adapted for the RI, the political distance model can also be adapted and implemented into the index.

As can be seen, the flexibility of the RI makes it a tool potentially of use in both in academia and the business world. The RI addresses many of the limitations of the CD model, thus giving it more credibility for both practitioner and researcher. The CD model is one dimensional in the sense that the difference between two countries is the same no matter which country is the home country and which country is the host country. The RI takes this into consideration with the addition of several other important variables. For 
example, it adds entry mode and days to start a business are based on host country factors.

Another drawback of the CD model is that the data used were gathered between 1967 and 1972. The data were from one U.S. company, IBM, and only management personnel filled out the surveys. On the other hand, RI uses data collected on an ongoing basis. The days to start a business data is collected by World Bank on a yearly basis as is the entry mode data from ease of doing business. The World Governance Indicators are collected yearly. Thomson Reuters collects the Asset 4 ESG data on a yearly basis. CO uses data from the World Values Survey, which is collected in waves every four years. The only data not updated, so to speak, is the geographic distance between capitals. This is updated as need be such as when a country may split or when it might reunite, such as Germany when they consolidated with the German Democratic Republic.

For those concerned with the "distance" metaphor, the term "distance" is only used with geographic distance. All of the other variables used are named according to the purpose of the data gathered. Contrary to the CD model, the name of the RI is such that it will not carry the implication of physical distance. Since Hofstede’s numbers have not been updated, the CD numbers have remained the same for almost 30 years and can be seen as fixed. However, the RI is continually changing as the data are updated from year to year.

\section{How to Measure Resistance}

The RI is based on the premise that it is a potentially useful tool for international expansion decision making. The method used for calculating resistance is based on Hofstede's method when he explained his culture dimensions and how they were 
measured. Hofstede gives the range and interpretation of his data. I quote from his web site:

The scale runs from 0 - 100 with 50 as a midlevel. The rule of thumb is that if a score is under 50 the culture scores relatively LOW on that scale and if any score is over 50 the culture scores HIGH on that scale. In the case of IDV - the LOW side (under 50) is considered 'Collectivist' and above 50 considered 'Individualist'. A country with a score of 43 would be collectivist but less collectivist than someone with 28 who is moving down toward the 0 mark.

As we can see from his explanation, Hofstede gives a range, a midpoint, and interpretation of the meanings that can be ascertained from the results.

The reasoning behind the RI measurement is this same as Hofstede's. There are several factors in the equation, but when they are all converted to the same scale of 0 to 1 they can be compared equally. As noted before, 1+ is added to the equation to prevent any variable from equaling 0 , which would then render the equation useless. Therefore, we can find the range of the RI by multiplying the lowest number, one, six times for each variable. Thus the lowest end of the RI range is one. We find the upper limit of the range by multiplying two times six which results in 12 . Accordingly, the RI produces a range between 1 and 12. The midpoint is $6.5(12-1=11 / 2=5.5+1=6.5)$ and, using Hofstede's logic, the higher the number the model produces above this point, the more difficult for the firm to succeed in the questioned market. If the model produces a number below 6.5, this would indicate an easier entry into the market in question. And continuing using this same logic, if the resistance number produced is 4.2 , entry is easier than it would be if the number were greater than 4.2, but more difficult than if it were a lower number such as 2.4. 
Another feature of the RI that is of particular interest, especially to practitioners, is the production of the top ten variables that have the highest input into the calculation. As stated before, the higher the number for a variable the more difficult that area is or the more resistance the firm will be faced with in that area. Use of this feature will help managers in understanding the most difficult parts of the venture and give the practitioner an opportunity to address these issues before commencing with the venture.

Strengths of the Model

One of the strengths of the RI is the fact that it contains full data for 214 countries. This is possibly the most comprehensive set of country data used in any model for research in international business expansion. Having such a large number of countries keeps all users of the index away from having the problem described by Franke \& Richey Jr (2010): "Regardless of the care taken in other aspects of research design, comparing small numbers of countries will hamper successful generalizations in IB research” (p1290). Franke \& Richey Jr. also endorse the use of a broad "array of settings, measures, and methods" (p1290).

Coopetition is a novel idea introduced by Luo (2004). Luo discusses the role of government interacting with MNCs as both, the government and the MNC, having their own agendas which may be competing with one another, but also realizing they must cooperate with one another. He also points out that there is a big difference between governments of emerging markets and governments of developed markets. The WGI database takes into consideration government factors and allows the RI to employ these differences in the outcomes of the resistance factor. Luo's research also deals with firm 
attributes and how they play a part in negotiations with governments. Many of the attributes mentioned are covered in the ESG database used like a lubricant to smooth the expansion. This corresponds to what Luo is purporting in his paper. In a similar vein, Witt \& Redding (2009) look at the differences of executives and how they perceive economic environments. The authors believe that executives' perspectives are important in decision making with regards to international business. They quote Ralston et. al. (1997) "When an individual incorporates both national culture influences and economic ideology influences synergistically to form a unique value system that is different from the value set supported by either national culture or economic ideology” (183). This is a perfect example of the need for models that incorporate more than just one variable like CD. The most interesting part of this statement is that all three of the areas of concern are covered by the RI. Practitioners can use the RI to evaluate different countries they may be interested in expanding to and choose accordingly. For example, should a firm choose between going to Colombia or Vietnam? This is not a simple one dimensional decision that needs to be made but one that involves many factors. For example, according to the CD model, the distance from the United States to Colombia is 4.3 and to Vietnam it is 3.7. Using the CD model, a firm would be inclined to expand into Vietnam as opposed to Colombia. But when we take a closer look at the situation, we can see the geographic distance is considerably different. This difference has to have an effect on shipping costs and time to receive goods. Colombia is Spanish speaking, which is a familiar language to a lot of people in the United States, but the Vietnamese language is not familiar to most people in the United States. This language barrier could create difficulties in contract negotiations. From this example, we can see some of the drawbacks of the CD model. 
The RI for this same scenario shows a greater resistance in going to Vietnam than going to Colombia from the United States. In the RI, a firm can customize the input factors they desire to look at and weigh them accordingly and then make comparisons. In this example, they could input language differences as a variable, and if the products involved are time sensitive, they can weigh the geographic distance more heavily than other variables.

\section{Conclusion}

In the world of international business, both practitioner and researcher look for ways to better understand cross-border expansion. Theories such as transaction cost have been used for decades to explain this expansion, and the RI is a tool that assimilates the bases of transaction cost to better enlighten our understanding of this process. Other theories such as institutional theory and the eclectic paradigm can also be merged into the RI model and, to a certain extent, already have been incorporated, with the inclusion of the geographic distance variable and firm variables through Asset 4 ESG. Other theories could be integrated and the RI expanded or contracted according to the needs of the user. As can be seen, the strength of the RI is its flexibility.

The RI was created to be more comprehensive for international expansion than the CD index. As explained previously, the CD model is based on limited elements while the RI fewer limitations. As Luo and Shenkar (2011) state, “The fixation on cultural 'distance’ has clearly constrained the scope of theory development in international business” (p12). The RI is a movement away from this "fixation" into an area of unlimited possibilities. 
An undertaking of this magnitude is not without its limitations. The RI has incorporated variables that were deemed pertinent for consideration to international expansion. However, it would be difficult to conceive that all variables of interest could be incorporated into one index. If a researcher does not want to use the CSA, FSA, and GSA format, it is understandable. Kwon and Konopa (1993) found no significance for geographic distance in their research. Therefore, it may be argued that it should not be used in the RI.

Using Asset 4 ESG, while considered one of the best measures of sustainability, could be construed as less rigorous than the Bloomberg ESG data or Goldman Sachs’ ESG. Therefore Asset 4 ESG could be replaced by either one of these datasets. It is also possible to contend that ESG does not adequately describe the firm's capabilities of expanding internationally. Firms may have proprietary capabilities that they want to figure into the equation instead of ESG. Researchers may want to use industry variables instead of firm variables to better understand the phenomenon of interest.

The variables of interest used in the model may constitute a limit to the RI, but its flexibility more than compensates for this limitation. This flexibility also makes the RI a tool with unlimited potential. The world of business, and international business in particular, is always changing, evolving, and growing. The RI is capable of changing with the addition or subtraction of variables. The RI is evolving into a more sophisticated index as weights and exponents are adjusted to meet the varying needs of businesses. The $\mathrm{RI}$ is capable of growing into as complex an indicator as a researcher or practitioner may need. 
It is unknown what the future of international business will be, but we can rest assured that it will consist of new theories, new datasets, new phenomena of interest and new approaches to deal with these changes. With the RI, researchers will have a tool that is capable of integrating the changes in all of these arenas. Practitioners will be able to use the RI to better understand the changes and help formulate new strategies as needed in the future. 


\section{STUDY TWO}

\section{Introduction}

The subject of culture and the role it plays has been the study of researchers for many years. The Malinowskian Delemma (1922) questioned how researchers can look at different cultures and make unbiased assumptions about those cultures. Today the debates still linger on how best to look at culture and its effect on business decisions. In 1980 Geert Hofstede published “Cultures Consequences” in which he classified national cultures by four dimensions. These dimensions have been used extensively in many areas of business analysis. Kogut and Singh (1988) created an index for measuring “distance” between countries based on Hofstede's dimensions.

$$
C D_{j}=\sum_{i=1}^{4}\left\{\left(I_{i j}-I_{i u}\right)^{2} / V_{i}\right\} / 4
$$

Where $I_{i j}$ stands for the index for the ith cultural dimension and jth country, $V_{i}$ is the variance of the index of the ith dimension, $u$ indicates the United States, and $C_{j}$ is the cultural difference of the jth country from the United States (Kogut \& Singh, 1988; p. 422). This index has become known as the Cultural Distance index (CD) and has been widely used by researchers as well as practitioners.

As of 2017 the simplistic measures of the CD model continue to make it popular. Still, there is a question of the usefulness of the CD model. Harzing, and Pudelko’s (2016) paper is entitled “Do we need to distance ourselves from the distance concept? Why home and host country context might matter more than (cultural) distance.” While Zaheer et al. (2012) say “international management is management of distance’’(p. 19), 
Harzing and Pudelko (2016) found that “ the explanatory power of distance is highly limited once home and host country context are accounted for" (p. 1). Consequently, they call for a more comprehensive advanced model.

Popli and Kumar (2015) state in response to the many pleas for more advanced models, "We respond to the calls of prominent scholars for novel conceptual efforts (Shenkar, 2001, 2012; Tung and Verbeke, 2010; Zaheer, Schomaker, and Nachum, 2012) in a more holistic manner to capture the effect of CD. Specifically, we reflect and build on the argument that 'the firm itself plays a role in the ramifications of distance' (Zaheer et al., 2012, p. 24)” (p. 528). However, their answer is the marginal cultural distance model (MCD), and it too uses the CD model of Kogut and Singh. Thus, it is vulnerable to the same criticism as this component.

One outcome of this critical examination of the $\mathrm{CD}$ is the realization of a need for a more comprehensive model. A model is needed that can consider different aspects of business and incorporate several dimensions into one index. The Resistance Index (RI) was created to meet the needs of practitioners dealing with global expansion and researchers looking for a more robust index to explain the many varied facets involved in international expansion.

As pointed out by Shenkar (2001), the Cultural Distance (CD) model is often used when looking at success or failure of an international venture. In Shenkar's (2001) awardwinning paper, he systematically critiques the aforementioned CD model. In one of the most notable and probably most quoted statements, Shenkar states, "The appeal of the CD construct is, unfortunately, illusory” (p. 520), going on to state the problems of CD 
and the reason for the paper. He says of the CD model, "It masks serious problems in conceptualization and measurement, from unsupported hidden assumptions to questionable methodological properties, undermining the validity of the construct and challenging its theoretical role and application” (p. 520).

The RI attempts to address these issues with a more advanced and comprehensive index. The RI is constructed so that it is flexible yet powerful. It takes into consideration three different areas of concern: firm specific advantages (FSA), country specific advantages (CSA), and government specific advantages (GSA). These areas are covered using different databases, all readily available with the exception of Asset 4 ESG (ESG) which is used for FSA. GSA is covered by the World Governance Indicators (WGI) from World Bank and uses six categories: Voice and Accountability, Political Stability and Absence of Violence, Government Effectiveness, Regulatory Quality, Rule of Law, and Control of Corruption. CSA is represented by the following: Entry Mode (derived from Ease of Doing Business from the World Bank; Geographic Distance (from capital cities to capital city); Days to Start a Business (from World Bank); and the Cultural Overlap model (from Maseland, 2011) which uses data from the World Values Survey (WVS). The inclusion of these different aspects should result in a robust index that may be more accurate in making predictions than the CD.

\section{Literature Review}

The CD was created in 1988, but this was not the first attempt at measuring differences between countries. In 1977 Johanson and Vahlne (1977) introduced the "psychic distance" model, since used extensively as is corroborated by the fact that is has over 10,000 Google citations. Other researchers have created models trying to measuring 
international expansion with less success (e.g. Berry, Guillen \& Zhou, 2010; Popli \& Kumar, 2015).

To this end, Nebus, and Chai, (2014) state the following:

The IB literature of the past thirty-five years which addresses the concept of 'psychic distance,' and its offshoot 'cultural distance,' can be characterized as nothing short of prolific, pervasive, and provocative. The literature is prolific as more than seventy nine empirical studies include psychic or cultural distance as an antecedent or moderator (Harzing and Christensen, 2004; Kirkman, Lowe and Gibson, 2006; Tihanyi, Griffith and Russel, 2005). It is pervasive as it has been used to explain many different outcomes in different literature streams from entry mode (Kogut and Singh, 1988; Morosini, Shane and Singh, 1998; Reuss and Lamont, 2009), export behavior and trade flows (Brewer, 2007;Dow, 2000;Dow, Douglas, and Karunaratna, 2006), sequence of internationalization (Nordstrom and Vahlne, 1994), to strategy (Sousa and Bradley, 2006) and organizational performance (Evans and Mavondo, 2002; Holzmüller and Kasper, 1991). Finally, it has been provocative in that there have been no less than twelve theoretical articles whose sole purpose is criticizing or commenting on the psychic, or cultural, distance construct or its operationalization (Bae and Salomon, 2010; Drogendijk and Zander, 2010; Evans, Treadgold and Mavondo, 2000; Shenkar, 2001, 2012; Shenkar, Luo and Yeheskel, 2008; Smith, 2010; Stöttinger and Schlegelmilch, 2000; Tung and Verbake, 2010; Zaheer, Schomaker and Nachum, 2012) (p. 8).

Zaheer (1995) called attention to the idea of liability of foreignness. Liability of foreignness was used to show that differences between countries have an effect on the success of a foreign business. This has morphed into an area that encompasses many different aspects of business such as institutional distance, cultural distance, and geographic distance. Experience of a firm's top management team has been shown to help reduce the liability of foreignness (e.g. Miller and Eden, 2006; Zaheer and Mosakowski, 1997; Salomon and Wu, 2012). Liability of foreignness has certainly had a positive effect on the popularity of the CD model. 
The CD model is not only used for international management, but has found its way into the area of finance. Dodd, Frijns, and Gilbert (2015) look at the effect of CD on whether a firm decides to cross list their stock or not. The results indicate that it depends on whether the firm is from an emerging country or not. "We document that cultural proximity is an important consideration for cross-listing destination for companies from developed markets but appears to be dominated by other motivations for companies from emerging markets” (p. 738).

Another way in which CD is used is to explain interstate conflict. For example, Bove, and Gokmen (2016) take an interesting slant on CD in their article titled "Cultural distance and interstate conflicts.” Their research shows, “The empirical evidence points consistently towards the importance of cultural distance in explaining the odds of interstate conflict” (p. 10). However, they use three different types of measurements for cultural distance: the CD model, the improved model by Kandogan, and a model based on the WVS, and all show how important CD can be regardless of the way measured.

Colakoglu and Caligiuri (2008) look at the CD effect on expatriates and found that the higher the $\mathrm{CD}$, the higher percentage of expatriates there are and the lower the subsidiary performance. If there is a greater need for home office control required by greater CD, then it stands to reason, as Black, Mendenhall, and Oddou (1991) said, that training in this area is of vital importance.

While CD has enjoyed success in many facets of business, it has also encountered its share of criticism. Dikova and Sahib (2013) point out several inconsistencies of CD. They used CD to look at cross border acquisitions and found that experience was the 
main factor of consequence. The authors also compared the 2004 nine-dimension GLOBE study to Hofstede and found similar results. Siegel, Licht, and Schwartz (2013) also used a Schwartz (1994) dimension called egalitarianism (equality) to test its effect on foreign direct investments (FDI). They found that egalitarianism was negatively related to FDI at a statistically significant level. They also found these results to be robust, even when using different measures: Hofstede’s (2001), GLOBE (House et al, 2004), and Power Distance (Berry et al. 2010). Research like this suggests we need to use more than just a cultural dimension when looking at international expansion.

Ahammad, Tarba, Liu, and Glaister (2016), who give many examples of recent research and the results, state the following:

The exploration of cross-cultural differences in merger and acquisition (M and A) has yielded inconsistent and perplexing findings (Gomes, Angwin, Weber, and Tarba, 2013; Gomes, Weber, Brown, and Tarba, 2011; Teerikangas and Very, 2006; Weber and Tarba, 2012; Weber, Tarba, and Reichel, 2009, 2011). Several studies conducted in the last two decades show that cultural differences have a negative effect on $\mathrm{M}$ and A performance, but other studies have explicitly indicated that cross-cultural differences affect both negatively and positively $\mathrm{M}$ and A performance (e.g., Ahammad and Glaister, 2011a, 2011b; Reus and Lamont, 2009; Sarala and Vaara, 2010; Slangen, 2006; Vaara, Sarala, Stahl, and Bjo"rkman, 2012; Weber, Tarba, and Rozen Bachar, 2011; Weber, Tarba, Stahl, and Rozen Bachar, 2012) (p. 66).

These authors look at the national culture versus the organizational culture and find a negative relationship on performance if the two types of culture are different.

Nebus and Chai (2014) make a good point when they ask the question: should we just jettison the model? The answer they give is no; however, to many researchers the answer is not clear. Do we continue to use a model that has dubious results and call it 
significant research, or do we in fact jettison the model? Until we have something better in place, we may never agree on the answer to this question.

In light of this dilemma, the RI was created. The object of this paper is to understand the advantages of the RI and to explore whether it provides a useful supplement to $\mathrm{CD}$, or even a possible replacement. Consequently, this paper will systematically compare the two models.

Comparison of CD and the RI

Shenkar (2001) points out several areas of concern regarding the CD model in his paper. Each of these will be covered point by point and compared with the RI. Shenkar's (2001) first point is "the use of CD in the foreign investment literature" (p. 520). He critiques the use of $\mathrm{CD}$ in foreign investment decision making concerning which countries provide a favorable setting for international expansion. The theory is that the greater the CD between two countries, the less likely a firm would be successful in an investment. The research that has been done has produced mixed results.

One feature of the RI is that it enables identification of the variables that have the highest significance in the calculation allowing analysis of the favorability (or lack thereof) for international expansion. Using this feature will help in understanding the most difficult parts of the venture and give the practitioner an opportunity to address these issues before commencing with the venture.

The CD model has other flaws, as pointed out by Beugelsdijk et al. (2015) in their development of the cultural overlap model. The CD is mean based, but Beugelsdijk et al. 
believe the more appropriate measure would be variance based. They develop a variance based model by using WVS, which uses individual responses to ten questions contained in the database. This cultural overlap model uses these values to then determine "cultural distance" as they call it, but I would prefer to call it "similarities” as used by Maseland (2011). They empirically tested the variance based model and found it to be "a more accurate proxy of the liabilities of foreignness faced by internationalizing firms than traditional mean-based measures of CD do” (p. 179). Au (1999) also proposed a variance method for looking at culture with the intra cultural variation (ICV). Once again WVS is used, because it samples many individuals from different demographics over different periods of time, thereby addressing some of the drawbacks of Hofstede's research. However, since the CD model is a mean based index, which is one of the reasons for its being criticized. It is interesting to note that Kogut and Singh themselves stated in their seminal piece, “The results should be interpreted with care” (p. 427). Another critique of the CD model is that it has been used with little critical attention, which is obviously contrary to what the authors had in mind. Taras, Steel, and Kirkman (2016) also weigh in on the extensive uses of CD. They voice the same concerns that Beugelsdijk et al. (2015) have, quoting Tov and Diener (2009, p. 33) who warn, "By equating entire nations with single cultures, we risk overlooking important differences within nations, as well as similarities that extend beyond national borders." This is further justification for the use of CO as one component of the RI. Beugelsdijk and Maseland (2010) attest to the use of culture in the realm of economics and how it helps in building a "more comprehensive and realistic theory” (p. 75). 
Taking the idea of variance a step farther, Axelrod (1997) addressed the convergence or divergence of cultures. Axelrod's model helps to explain why we have regions, nations, and so forth due to commonalities and how these beliefs transition over boundaries, "It treats culture as the attributes that social influence can influence" (p. 222). This would be consistent with the idea of using WVS data since these data are on an individual level and thus take into consideration what Axelrod demonstrates can be influenced and what cannot be influenced on the individual level that will have an effect on culture. Understanding how different influences might affect outcomes is important in understanding international business. Williamson (1981) was well aware of the need to consider more than one influence when he quoted Friedrich A. Hayek, "his (Friedrich A. Hayek) insistence that attention to the details of social processes and economic institutions was made necessary by the 'unavoidable imperfection of man's knowledge' (1945, p. 530)” (p. 1541).

To take this idea a step further, Johnson, Lenartowicz, and Apud (2006), in their study of cross cultural competence (CCC), found that "studies of CC in IB tend to ignore the larger environments in which expatriate managers operate: the economic, political, and technological environments, for example, that can make an overseas assignment particularly challenging, as well as the contextual influences that can impede effective cross-cultural communication (Von Glinow et al., 2004)” (p. 526). They assert that research is being confounded by other variables not taken into consideration such as language, economy, politics, and legal systems, while recognizing that knowledge of culture is also important. 
The RI takes into consideration many of the aspects these authors bring to light. Using the WGI data takes into consideration the political issue by looking at the political stability of a country, the control of corruption, and other factors. The economic concern is addressed by using data on contract enforcement, openness of people to foreign investments, and other similar variables. RI attempts to address the concerns about contextual influences by incorporating data from Asset 4 ESG. In the social category of ESG, a firm's training program is rated according to international components. The board is evaluated on its national diversity, since the more diversified the board is, the more capable it is of understanding different cultures, and the better to assimilate them into the corporate culture. Black, Mendenhall, and Oddou (1991) state, “Cross-cultural training enables the individual to learn both content and skills that will facilitate effective crosscultural interaction by reducing misunderstandings and inappropriate behaviors” (p. 120). Johnson, Lenartowicz, and Apud also state, "the inability of firms and their managers to adjust to the demands of the international business environment has been advanced as a primary cause of international business failures (Tung, 1982; Doremus et al., 1998; Ricks, 1999; Apud et al., 2003)” (p. 525).

Ambos and Håkanson (2014) also call the use of the metaphor "distance” into question as well as the CD model, of which they state, "The popularity of the index was primarily due to the ease of its computation with little or no consideration of its validity and reliability” (p. 2). They even call into question Hofstede's data, given it was done only within one large U.S. based company (IBM) and the survey was only given to the management personnel. They even go so far as to state the use is "untenable", citing other 
articles (Brewer, 2007; Håkanson and Ambos, 2010; Harzing and Christensen, 2004; Sousa and Bradley, 2006; Stöttinger and Schlegelmilch, 1998) as corroboration.

The RI is easy to use since it is a multiplicative index that includes data from well-known sources (e.g., World Bank and World Values Survey). The ease of use is complimented by the comprehensiveness of the index. This comprehensiveness is accomplished with variables covering areas of government, country, and firm. Incorporating these diverse variables adds to the validity of the model, while the use of well-known databases adds to its reliability.

There are other drawbacks to the Hofstede data as pointed out by Taras, Steel, and Kirkman (2012). They point out how problematic it is to use data collected from 1967 to 1973 fifty years later. Again, these issues are avoided in the RI by using databases that are updated systematically on a yearly basis. The WVS, used in calculating the CO, is collected every four years but this is still better than using older, static data.

Concerning entry mode, Shenkar goes on to mention that the results of many studies are mixed (Benito and Grisprud, 1992; Padmanabhan and Cho, 1996). He cites many situations regarding $\mathrm{CD}$ and foreign direct investment (FDI), calling attention to the different results produced. The theory underlying Shenkar's study is the closer the cultural distance, the less control that is needed, whereas the greater the distance, the more control is needed. Entry mode is then based on control, for example greenfield (constructing new facilities outside of parent country) or acquisition (greater control) would be used when there is greater $\mathrm{CD}$, but exporting or licensing (less control) would be used for closer proximities. From a transaction cost economics point of view, the more 
distant the country, the higher the transaction costs for several reasons such as transportation costs (Kwon and Konopa, 1993) or transferring of capabilities (Buckley and Casson, 1976; Scott, 2003). The bottom line is that, while CD is used to predict entry mode, the CD model only considers entry mode from one perspective, the cultural dimensions defined by Hofstede. As Shenkar points out "Gatignon and Anderson (1988) acknowledge that CD does not fit very well within the transaction costs argument” (p. 521).

The RI has a component for entry mode and evaluates each scenario on the bases of which entry mode is chosen. The RI uses five types of entry mode: licensing, exporting, joint venture, greenfield, and acquisition. Each entry mode is weighted differently based on the difficulty to achieve each entry mode. For example, to do licensing is a matter of contracts between two parties, generally not very difficult. An acquisition, on the other hand, is very difficult because an equity investment, meshing of personnel, and overcoming cultural differences must all be taken into consideration (Buono and Bowditch, 1989; Elsass and Veiga, 1994; Very, Lubatkin, and Calori, 1996). Joint ventures are somewhere in between, with more difficulty than licensing but less than acquisitions, because there is a partner involved who should make some of the transitions easier and possibly share the equity outlay. Therefore, the advantage of the RI model is that it incorporates entry mode.

From a transaction cost point of view, as Shenkar points out, results using the CD model are mixed; consequently, we cannot assume that $\mathrm{CD}$ alone is responsible for results. As mentioned before, Williamson points out the need for more factors to be 
considered when looking at transaction costs and international expansion. The RI model takes many factors into consideration that can help explain cost transactions. The RI looks at the government of the host country, its ability to enforce rules and contracts, the stability of the government, and its level of corruption. Since all of these factors are taken into consideration, as well as geographic distance that may affect transportation costs and firm capabilities, the RI is a relatively comprehensive instrument with regards to transaction costs.

The third main point Shenkar makes concerns affiliate performance. Again, he points out results cited from other authors such as Park and Ungson (1997) who report that the greater the cultural distance, the better the success rate of joint ventures. Kogut and Singh (1988) reported findings in opposition to Park and Ungson’s (1997) findings indicating the greater the distance the less chance of success. Again, the RI is designed to provide a more detailed analysis of issues like poor affiliate performance by the use of firm variables that will aid in the successful transition and incorporation of affiliates. This is accomplished through eighteen subcategories of the Asset 4 ESG database by Thomson Reuters. These subcategories cover such things as board diversification and international training of employees, as well as other variables valuable in international expansion. Consequently, the RI model figures into its calculations the ability of the firm to cope with international expansion, giving these firms a better chance of success. Another factor is that lower scores on Asset 4 ESG data suggest a firm is not well equipped to handle the various obstacles they will be confronted with undertaking an international expansion. 
Hidden Assumptions, Conceptual Properties, and Methodological Issues

Shenkar next looks at what he calls "hidden assumptions" of the CD model and categorizes them into two groups, conceptual properties and methodological properties. Shenkar defines each area as follows: "Conceptual properties produce illusions that are the core of the CD construct and undermine its validity within the context of FDI theories. Methodological properties present instrumentation and measurement biases that distort the accurate measurement of cultural differences; they are most closely associated with the Kogut and Singh (1988) index but address broader measurement issues as well” (p. 522-523).

Shenkar breaks down conceptual properties into five areas. His first point is the illusion of symmetry (p. 523). Distance, by definition, is symmetric. The distance from point A to point B is identical to the distance from point B to point A. Shenkar points out this is an illusion because with geographic distance it is symmetrical, but when looking at countries, it may be different for a firm from country A going to country B than it is for a firm from country B going to country A. The CD model does not consider this difference, as the model produces the same number regardless of direction of movement. Thus, it implies that it is no more difficult for a firm from a developing country to go to a developed country than it is for a firm to go from a developed country to a developing country. Researchers and practitioners alike know this not to be the case, and that the differences are part of what requires different strategies.

The RI is well suited to address this situation in the method for handling data, because it looks at government variables based on the host country. Consequently, there is generally a difference between the government of a developed and a developing 
country, and this difference is incorporated into the analysis. The other factor that should be taken into consideration is the firm itself. Institutional theory tells us that a firm is influenced by other firms around it, and therefore it stands to reason that firms from different countries should be somewhat different from one another, but perhaps not so different from firms in the same country or other countries with similar governments. Again, this is taken into consideration by using the variables from the ESG database.

Shenkar's second point is the illusion of stability. Measured at a single point in time, CD is implicitly assumed to be constant (p. 523). Shenkar points out that there are several points of view that do not hold to the theory that culture changes very slowly. The CD model uses Hofstede's cultural dimensions from a study done in the late 60s and early 70s. For the CD model to be relevant it must assume that culture changes slowly and incrementally. It is over forty years since Hofstede collected his data. While he and other researchers have updated some of the data and expanded it slightly, much of it is still based on the original data collection. The numbers used for CD are based on the updated Hofstede numbers. But we must keep in mind that not all of the data were updated by resampling all of the management people in IBM, as was the situation in the first sample. So the problem remains that a lot of the data may be outdated and there is no systematic approach to collecting these data on an ongoing basis.

The RI model uses databases that are systematically updated regularly. The only data not updated is the geographic distance which remains constant unless there is a change in country status (new country created or two countries merge to form one), in which case the data are updated accordingly. The WGI data are updated yearly as are the ESG data. The WVS data are updated by waves in which data are collected over a four 
year period of time so new data are disseminated every four years. The other data base that is used to produce the weighted entry mode figures is updated annually. All of this has the effect of keeping the RI relevant over time. If the culture does change slowly, that will be shown in the waves from WVS and figured into the model. Therefore, the RI model does not have issues with measures becoming outdated.

Shenkar's third point is the illusion of linearity. Also embedded in the distance metaphor is the assumption of linear impact on investment, entry mode and performance (p. 523). Shenkar points out discrepancies in assuming that there is a certain sequence of events when choosing to use the CD model. Shenkar refers to expatriate literature and the fact that some research has shown that expatriates have issues with different cultures whether they are close or distant, citing Brewster (1995) and O'Grady and Lane (1996) as examples. The RI takes this human element into consideration in the calculation of the model. The model uses subcategories of Asset 4 ESG, of which several items point to employee preparation. One specific subcategory is international training which emphasizes the training, or lack thereof, of employees in order to educate them concerning international differences in diverse areas. This investment is intended to lower expatriate turnover and increase productivity. Several studies show that with cultural training there is marked improvement in expatriate performance (e.g., Colakoglu and Caligiuri,2008).

The fourth point is the illusion of causality. An implicit assumption in much of the literature is that CD has a causal effect on the FDI pattern, sequence, and performance. The connotation is that culture is the only determinant of distance with relevance to FDI (p. 524). Shenkar provides several examples of research that show many 
factors that contribute to decision making when international expansion is considered. Those factors range from geo-culture distance (Goodnow \& Hansz, 1972) to language (Buckley \& Casson, 1976) to political instability (Thunnell, 1977). Practitioners know that decisions of this nature and magnitude are not contingent on one factor such as the CD model.

Consequently, the RI model takes into consideration country variables, firm variables, and government variables. With reference to the three areas just mentioned, the reference to language was not taken into consideration in the RI. This was due to the difficulty of quantifying differences in languages. Most cases that use language and quantify it use 1 for same language and 0 for different. This does not take into consideration language commonalities. An individual who speaks Dutch, for example, generally can understand someone who speaks German because Dutch is a Germanic language, but is less likely to understand Arabic or Mandarin Chinese.

The RI does incorporate the area of political instability, mentioned by Thunnell (1977) in the use of the WGI database of which one of the six variables is Political Stability and Absence of Violence. The other variables, Voice and Accountability, Government Effectiveness, Regulatory Quality, Rule of Law, and Control of Corruption are also valuable in better understanding the political stability of a government.

Brown, Rugman and Verbeke (1989) argue that "the combination of economic and cultural factors creates firm specific assets, which can cause failure” (p. 524). They add to this analysis by bringing into the conversation the idea that a combination of factors may bring results that each individual variable would not show. The RI automatically incorporates this idea that results may differ in combination because 
cultural factors are considered with the inclusion of the cultural overlap model and economic factors are considered using WGI, Entry Mode, and Days to Start a Business. Since these variables are being combined into one model, the resulting analysis includes the combined effects of all the variables.

The fifth point in the conceptual properties area is the illusion of discordance. "The implicit assumption that differences in cultures produce lack of 'fit' and hence an obstacle to transaction is questionable” (p. 524). Shenkar's main point here is that there is such a thing as complimentary situations, and this would include cultures. Indeed, complementarity is the reason for most acquisitions and international joint ventures. Firms are looking for other firms that have something they need or want, and they can get that something by acquiring or partnering with another firm. A simple example is if a firm from country A wants access to the markets in country B, it might be easier to partner with a firm that already has a presence in the marketplace in country B than to enter directly and alone. A newer phenomenon now is the acquisition of a firm in country B that has certain tax advantages that would be beneficial for a firm from country A. This situation is hard to program into any model, and it is especially difficult to find a proxy that is predictably updated. But the main point is that the distance measure is not necessarily harmful as long as other factors are taken into consideration. The objective is to show precisely what Shenkar is referring to when he addresses the shortcomings of the CD model, in that there are factors other than CD involved in FDI. It is in this light that the RI has included the many variables it has in an attempt to cover as many considerations as possible when analyzing international expansion. RI incorporates seventeen variables for country factors, six governance factors, and eighteen firm factors. 
Moving on to what Shenkar calls the "Methodological Properties" (p. 524), he has three areas of concern, "The Assumption of Corporate Homogeneity, The Assumption of Spatial Homogeneity, and The Assumption of Equivalence” (p. 524-525).

The first area, The Assumption of Corporate Homogeneity, is “The CD index used to measure the construct relies on national culture measures and implicitly assumes lack of corporate culture variance, an assumption that lacks support (e.g., Hofstede, Neuijen, Ohavy and Sanders, 1990)” (p. 525). Shenkar uses the example that corporate culture may influence national culture beliefs, but points out that it may be for good or for bad, citing Laurent (1986) and Schneider (1988) as just two examples. As posited before, the CD model does nothing to consider direction of movement, and this is a similar situation with cultural variance. It stands to reason that if there are differences in national cultures, there would be differences in firm culture and national culture. The CD model only looks at national culture, although there are those who might argue since Hofstede gathered all of his data from one firm, IBM, that there might be a firm culture involved. This reasoning would then leave the CD model completely vulnerable to questions because it would only measure IBM's firm culture differences in different countries, not different country cultures. It does not appear other researchers believe Hofstede measured firm culture alone since they have used this measure for national culture for over forty years. However, we find another issue with the CD model as exposed by Shenkar. The RI has taken this issue of firm culture versus national culture into consideration and uses the ESG data as the measure of firm culture and CO as a measure of national culture. The ESG data are on a scale of 1 to 100 with 100 being the best. So if a company implements a rigorous international training program it may score 
100 , while a firm with no international training program may score a 0 . With eighteen categories covering firm governance, economics, social, and environmental concerns the RI attempts to quantify firm culture. Consequently, when researchers talk about the interaction of firm culture and national culture, both aspects can be considered in the RI.

The second point "The Assumption of Spatial Homogeneity” (p. 525) is defined as "Measuring distance from one national culture to another, the CD index assumes uniformity within the national unit” (p. 525). Shenkar goes on to say "evidence suggests that intra-cultural variation explains as much if not more than intercultural variation ( $\mathrm{Au}$, 2000)” (p. 525). The CD model, through the use of Hofstede’s numbers, assigns a number to a country, a technique brought into question by Shenkar (2001), Au (2000), and others. It is this situation that moved Maseland (2011) to create his CO model to measure culture. Instead of measuring the mean or average of the data Maseland uses a variance model that considers intra-cultural variation instead of inter cultural variation. This was the reason the CO model is used instead of the CD model to represent national culture in the RI. As mentioned previously in this paper, researchers have shown the CO model using variance to be preferred to the CD model that uses only mean.

The last point is "The Assumption of Equivalence" (p. 525). Shenkar points out that the CD model is suspect, just as Hofstede's data are suspect. The use of one company's data and the one-time collection of data caused Shenkar to break down the work into two areas of concern. The first area deals with the updating of the data. Shenkar points out that Hofstede did add a dimension, but it is seldom used and not well supported. However, Shenkar's attack on the updating of the model is not often done, since most researchers simply add something to the CD model. For example, when 
Hofstede updated his information or added another dimension, many researchers simply used the original CD model but modified it to reflect five dimensions instead of four. Others have used the GLOBE (House et al., 2004) data with the same model by incorporating these same changes. The idea is the same in that each GLOBE dimension is subtracted from the other with the difference squared and divided by the variance of the dimension, then divided by the total number of dimensions usually being nine with GLOBE. So in this sense the model is still used and considered relevant. In defense of Kogut and Singh, others (e.g., Popli and Kumar, 2015) have already made changes or "improvements" to the model. Given the wide acceptance and use of CD, many researchers probably see no reason to change the framework of the model. The RI includes multiple variables giving it a more comprehensive result. Yet these variables can be changed, deleted, or added to, and thus the RI lends itself to updating continuously. The present variables are continuously updated, so if the index is changed it can still be considered current as long as the existing variables are updated systematically. Therefore, the RI is not very vulnerable to becoming outdated.

The second point is the assumption that everything is equivalent. By this Shenkar means that some measures are more important from others, but this is not reflected in the CD model, although even Kogut and Singh demonstrate that some of the dimensions may be more influential than others. The CD model gives each dimension the same weight, thus those that may be more influential are not given adequate consideration. With the RI model, each variable, as well as each composite, can be weighted. So if the researcher wants to give international training a greater weight, it is possible within the RI. It is also possible to weight the overall composite such as the WGI factors. Weighting can be done 
in several ways such as using a multiplicative weight. For example, if the researcher believes training should be given double the value of the other ESG variables, the researcher simply denotes the weight of the variable in the formula. If the desire is to give more weight to the government section of the model, they can do the same thing, with that element. A strength of the RI is that if you believe a factor acts in a different manner such as growing exponentially, this too can be addressed.

In closing, Shenkar mentions that “the 'distance' metaphor is translated into a focus on what sets cultures apart but not on what might bring them together” (p. 526). The RI uses data that are mostly on a continuum of what could be considered most effective to least effective and as such shows how to bring together that which may be viewed as distant. As Shenkar has pointed out, the metaphor "distance" can cause a problem with interpretation, so this is a reason for not having a distance variable other than the geographic distance variable in the RI.

\section{Limitations}

One limitation of the RI is that it is so much more complex and harder to compute than $\mathrm{CD}$. While the strength of the RI is its comprehensiveness and flexibility, these characteristics can also be limitations. The RI can incorporate other data sets and updated versions of existing data sets, but whatever data are added must be in exactly the same form as the existing data sets. For example, if the new data set being added is based on countries, all of the countries in the new data set must be named exactly the same as they are in the other data sets being used. For example, you cannot have one data set using "Congo" and the other data set using the "Republic of Congo." Along this same line, the data sets in the RI are case sensitive. Therefore, you cannot have one data set with "The 
Bahamas” and the other data set with "the Bahamas.” Another limitation within data sets is that missing data must be handled in exactly the same manner. One data set cannot use NA while another data set uses 0 . These restrictions can be very difficult to identify and time consuming to correct when trying to compute the RI. Despite this limitation, the RI does meet the calls for theoretical advances beyond the CD (Berry et al., 2010; Håkanson and Ambos, 2010; Shenkar, 2001, 2012; Tihanyi et al., 2005; Zaheer et al., 2012).

\section{Conclusion}

The criticisms of the CD model have been addressed and the manner in which the RI handles these criticisms has been shown in this discussion. Overall, there are a number of limitations to the CD model that the RI addresses. The CD is mean based while the RI is variance based. The $\mathrm{CD}$ does not take contextual influences into consideration while the RI addresses this through multiple variables. The CD uses the "distance" metaphor whereas the RI uses the idea of "resistance.” The CD uses outdated data while the RI uses data gathered on a continual basis. Thus, the RI addresses the "hidden assumptions" Shenkar analyzes in the CD model.

Ambos and Håkanson (2014) present the following recommendations for creating more advanced models: (1) "when possible use more than one distance measure” (p. 5); (2) "aim for a closer link between the research question at hand and the measure employed” (p. 5); (3) “move away from the predominant perception of distance as something negative” (p. 6); (4) "recognize the existence of asymmetries and the importance of directionalities" (p. 6). They go on to state "New conceptualizations and a new terminology are needed that more clearly denote their theoretical basis, the assumptions upon which this rests, and the limits to their empirical applicability” (p. 6). 
The RI tries to answer this gap by introducing a more comprehensive model that will address these issues and more. The first recommendation is addressed with the use of more measures, although we do not call them "distance” to avoid the problematic metaphor as previously mentioned. The second recommendation is addressed by the flexibility of the RI, enabling researchers to address specific questions in many area of research. The third recommendation is addressed by only using distance as a geographic variable. The other variables, such as Entry Mode and Days to Start a Business, do not carry negative connotations. And finally, the fourth recommendation is addressed by using data from home and host countries, therefore taking directionality into consideration.

Thus, I propose that the RI is capable of handling several variables and producing a result that may be more useful for international expansion than the CD model. The RI proposes a more advanced model that incorporates many validated variables to produce results that may be of value to not only researchers, but also to practitioners. The promise of being able to manipulate the model according to users' preferences brings an intriguing value to future users of the RI. The conceptual and theoretical research that can be accomplished with the RI is the contribution this index has to offer to the researcher and practitioner. The next step in assessing the value of the RI is to test it in some actual cases to see if the results yielded are of equal or better value than CD. 


\section{STUDY THREE}

Introduction

The success or failure of an international venture can mean the success or failure of a company. How to reduce the risk of failure is of vital importance to managers. As Hammond, Keeney, and Raiffa (1998) state in their Harvard Business Review article entitled "The hidden traps in decision making," "Where do bad decisions come from? Mostly from distortions and biases" (p.1). They go on to say that "the best protection against all psychological traps—in isolation or in combination-is awareness. Forewarned is forearmed” (p.10).

The RI is a newly developed tool designed to enable us to better understand international expansion of firms into particular countries, enabling managers to reduce the risk of failure. The RI is a comprehensive model that consists of variables from three different areas of interest: government, country, and firm. The government area utilizes the World Governance Indicators (WGI), of which there are six categories: Voice and Accountability, Political Stability and Absence of Violence, Government Effectiveness, Regulatory Quality, Rule of Law, and Control of Corruption. The country factors are represented by: the Cultural Overlap (CO) model (Maseland, 2011), which uses the World Values Survey; Time to Start a Business, which is from the World Bank Time to Start a Business; Geographic Distance, which is measured from capital city to capital city; and entry mode, which is from World Bank Ease of Doing Business. Firm factors

come from Thomson Reuters Asset 4 ESG. Taking all of these variables together, the RI 
looks at forty one different contributing factors to assess resistance to a given international expansion.

Using these three different groupings (i.e., government, country, and firm) the RI incorporates relevant aspects from different areas of concern for managers of firms planning international expansion, thereby producing results with which managers can make knowledgeable decisions. By taking so many factors into consideration, the RI helps managers to be aware of the many different factors they will be confronted with and what will be most problematic. For example, if the RI produces a high number, meaning the expansion in question will be difficult, the manager can look at the scores of particular variables to better understand what areas created this high score. When a high score is discovered within the variables, the manager knows that area is a weakness and should be addressed. For example, if there is a high score for international training, meaning the firm's training program is not internationally based, the manager may decide to reorganize the training program to be more inclusive of international methods.

Case studies are one of the best ways to delve more deeply into the various aspects of international expansion. There are different ways to present case studies and Cuervo-Cazurra, Newburry, and Park (2016) use a process method. To illustrate the reliability of the RI, this paper follows Cuervo-Cazurra et al. (2016), using their critique of three cases involved in choosing a country for expansion. The RI will be shown in relationship to their critique in order to demonstrate how the RI would be used to make well informed decisions. The CD will then be considered and compared to the RI. 
When looking at the choice of country, Cuervo-Cazurra et al. (2016) state “The greater challenge is to identify which particular country is the most appropriate for the company” (p. 31). The RI, by including firm, country, and government variables, attempts to help managers in making the decision of which country is most appropriate for international expansion. The scenarios of the company and possible host countries can be entered into the RI to produce results for each possible expansion. The scenario with the least resistance produced (the most favorable result) could be compared to the second possibility and so forth to rank countries of possible expansion for the managers. Then, managers could compare the highest contributing factors and decide if those factors can be influenced by the firm or not, which would aid in the decision making.

It is along these lines that we look at Cuervo-Cazurra et al. (2016) and see if the RI is capable of reflecting the concerns of each case study. This paper will analyze three cases covered by Cuervo-Cazurra et al. (2016) in their chapter “Country Selection.” The first case involves the Chinese automaker FAW and its expansion into Mexico; the second case involves Vale, the Brazilian iron ore producer, and its expansion into China; the third case involves Cemex, the Mexican cement producer, and its expansion into Colombia.

Case 1

FAW is one of the big four automakers in China along with Dongfeng Motor, SAIC Motor, and Changan Automobile. Grupo Salinas was looking to expand its operations in Mexico and signed a memorandum of understanding with FAW in 2007 (Cuervo-Cazurra et al., 2016). This venture was considered a failure, with FAW leaving 
the Mexican market in 2010 in part due to the world recession in 2008. However, Cuervo-Cazurra et al. (2016) go on to show that the recession was not the only problem incurred in this expansion.

\section{Critique of FAW}

The first thing to be considered with this critique is that FAW is not among the firms listed in Thomson Reuters Asset 4 ESG (ESG) database. However, in the over 3600 firms listed, there are other Chinese automobile manufacturers that can be used to represent FAW in our analysis. FAW is one of the top four automakers in China. The other three are Dongfeng Motor, SAIC Motor, and Changan Automobile. Dongfeng Motor is listed in the data set and, therefore, can be used as representative of FAW. Managers of firms not listed in the ESG dataset can use this same tactic in order to use the RI as a tool for better understanding their proposed international expansion. ESG has eighteen categories and managers can compare their firm to a representative firm in the database and generate an ESG dataset for their firm. Although Dongfeng Motor is not affiliated with FAW, since both companies are part of the big four Chinese automakers, most of the eighteen categories in ESG should be similar.

Substituting Dongfeng Motor for FAW, the RI can now be compared with the critique of Cuervo-Cazurra et al. (2016). By doing this comparison, a more in depth picture of what took place with the expansion of FAW into Mexico can be seen. CuervoCazurra et al. (2016) look at the market in Mexico, deem it ripe for FAW expansion, and also look at Grupo Salinas, who FAW partnered with in this venture. They go on to explain that these two companies seemed to complement each other, with Salina well 
established in the Mexican market and FAW a well-established automaker in China. The RI does not look at this apparent complementary fit, but simply looks at the type of entry mode. Joint venture is the type of entry mode used by these two firms and this would be considered a middle difficulty entry mode by the RI. The least difficult is licensing and the most difficult would be an acquisition (Buono \& Bowditch, 1989; Elsass \& Veiga, 1994; Very, Lubatkin, \& Calori, 1996). The RI uses entry mode based on host country and the ease of doing business in that country. For this scenario, the RI produced a number of 1.33 on a scale of 1 being easiest and 2 being most difficult. This would be in line with the rationale that a joint venture should not be difficult to establish, and this was in fact the case with FAW and Salinas.

While Salinas was the instigator of this venture, FAW must be seen as the firm of interest since they would be undertaking the international venture (Salinas would still be doing business domestically). Cuervo-Cazurra et al. (2016) mention the management of Salinas but not of FAW. However, they draw no conclusions about FAW's international capabilities. Nevertheless, research has shown that the firm's ability to expand internationally depends on the firm's ability in areas such as training programs (Colakoglu \& Caligiuri, 2008) and top management team national diversity (Neilsen \& Neilsen, 2013).

The RI looks at the firm through ESG and the RI for this category is 1.76. Again, Dongfeng is used as a substitute for FAW. As can be seen from Table 1, ESG shows four main categories: corporate governance, economic, environmental, and social. Within these four categories there are eighteen sub-categories from which the firm's capabilities 
of international expansion with the RI can be assessed. Table 1 shows the raw data from ESG based on a scale from 0 to 100 . The higher the score, the better the firm is in that category. Therefore, the lower the score, the less prepared the company would be for international expansion. Upon inspection of the table we can see some very low numbers (e.g., Board of Directors/Board Functions 3.52).

One of the advantages of RI is that we can get a better understanding of each category by including the eighteen sub categories. When examining these sub categories, we get a better understanding of the company's ability to go abroad. The first category is Corporate Governance, which is broken down into five sub categories. Compensation is mid-level, but the rest of the sub-categories are very low. Board Functions is the lowest factor of this group and may be a cause of cultural insularity showing the company may not be as adaptive as required for international expansion. According to Thomson Reuters, the definition for structure is "It reflects a company's capacity to ensure a critical exchange of ideas and an independent decision-making process through an experienced, diverse and independent board” (Asset 4 ESG data glossary). As mentioned before, diversification of the board is very important to the success of a firm in international expansion. The Vision and Strategy sub category looks at the ability of the board to incorporate all aspects of the four categories into a vision for the firm and its strategic management decisions. Shareholders Rights takes into consideration the attractiveness of a firm to minority shareholders. This area may not appear to be important in this situation since it is a joint venture, but it may give us insight into the public's view of a firm. Cuervo-Cazurra et al. (2016) addressed the public opinion of the Mexican people with 
regards to Chinese automobiles, saying "Mexican consumers shunned the Chinese-made cars, as they were suspicious of the reliability of the Chinese brand” (p. 34).

Looking at the Economic category, it would appear this category is also low, with the exception of performance. Profitability/Shareholder Loyalty is low, but not in comparison to the Corporate Governance category. This sub category is self-explanatory and measures the firm's commitment to these areas. Revenue/Client Loyalty is the lowest indicator in this category and looks at the company's capacity to grow. This may be an indication of inexperience in international expansion or an indication that international expansion is not valued by the firm.

In the Environmental category we a find product innovation very high, but the rest of the category is low. The Emission Reduction sub category addresses the company's commitment to controlling environmental emissions. Cuervo-Cazurra et al. (2016), when talking about the difficulty of FAW to send vehicles to the U. S. and Canada, stated that the cars produced by FAW were unable to meet safety and emission standards required by DOT in the United States. Resource Reduction is concerned with eco-efficient solutions and more efficient supply chain management. When considering international expansion, this area may show how well a firm is prepared for taking on the more intricate details of international supply chain management. Another factor that should be considered when looking at the Environmental category is the public view toward the firm in light of its environmental practices. This may have an effect on the brand popularity, or lack thereof. 
The Social category has all seven sub-categories rated as low. Of these sub categories, Customer/Product Responsibility is the lowest. This sub category looks at creating value-added products and services. Scoring low in this category may add credence to the Mexican people's opinion that Chinese automobiles were not reliable (Cuervo-Cazurra et al., 2016). The Society /Community sub category is concerned with the company's reputation and may be viewed as complementary to the previous sub category. Both of these sub-categories measure at how well a firm positions itself with reference to its brand image. The sub category Human Rights is self-explanatory and again may have a positive or negative affect on the company from a consumer's point of view. The Workforce/Diversity Opportunity sub category looks at management's commitment to diversity of its employees. It also looks at the issue of equality of opportunity regardless of race, gender, age, etc. Dealing with a diverse workforce may help management with international expansion (Bartlett \& Ghoshal, 1989; Harzing, 2000; Leung \& Peterson, 2011). Employment Quality, concerned with workforce loyalty and productivity, is the highest score in the Social category. Health and Safety is also high in this category. Employment Quality and Health and Safety, when taken together, indicate the firm's commitment to its employees. The last sub category, Training and Development, is based on the development of the employee. This includes training programs and whether the training programs are internationally focused. Training and Development is instrumental in the success of firms pursuing cross border expansion (Black, Mendenhall, \& Oddou, 1991). 
TABLE 1 Dongfeng Motor ESG

$\begin{array}{lc}\text { CORPORATE GOVERNANCE } & \\ \text { DONGFENG MOTOR GP.'H' - Board of Directors/Board Functions } & 3.52 \\ \text { DONGFENG MOTOR GP.'H' - Board of Directors/Board Structure } & 11.12 \\ \text { DONGFENG MOTOR GP.'H' - Board of Directors/Compensation Policy } & 45.53 \\ \text { DONGFENG MOTOR GP.'H' - Integration/Vision and Strategy } & 15.28 \\ \text { DONGFENG MOTOR GP.'H' - Shareholders /Shareholder Rights } & 8.82 \\ \text { ECONOMIC } & \\ \text { DONGFENG MOTOR GP.'H' - Margins /Performance } & 51.87 \\ \text { DONGFENG MOTOR GP.'H' - Profitability /Shareholder Loyalty } & 37.28 \\ \text { DONGFENG MOTOR GP.'H' - Revenue /Client Loyalty } & 24.29 \\ \text { ENVIRONMENTAL } & 15.28 \\ \text { DONGFENG MOTOR GP.'H' - Emission Reduction } & 76.3 \\ \text { DONGFENG MOTOR GP.'H' - Product Innovation } & 11.66 \\ \text { DONGFENG MOTOR GP.'H' - Resource Reduction } & \\ \text { SOCIAL } & 3.84 \\ \text { DONGFENG MOTOR GP.'H' - Customer /Product Responsibility } & 12.93 \\ \text { DONGFENG MOTOR GP.'H' - Society /Community } & 25.6 \\ \text { DONGFENG MOTOR GP.'H' - Society /Human Rights } & 10.02 \\ \text { DONGFENG MOTOR GP.'H' - Workforce /Diversity and Opportunity } & 37.63 \\ \text { DONGFENG MOTOR GP.'H' - Workforce /Employment Quality } & 28.13 \\ \text { DONGFENG MOTOR GP.'H' - Workforce /Health \& Safety } & 22.05 \\ \text { DONGFENG MOTOR GP.'H' - Workforce /Training and Development } & \end{array}$

Cuervo-Cazurra et al. (2016) mention other areas in their critique. For example, they refer to an increase in taxes, an increase in vehicles fees, etc. that may have had a detrimental effect on the venture. They also mention that FAW cars did not meet requirements of DOT in the United States. All of these factors involve government regulations that the RI takes into consideration. While the RI does not take specifics, such as taxes, into consideration, it does use six different categories to assess the government. A shortcoming of the RI is that it cannot take into consideration two different countries' legal systems. For example, the United States government's DOT regulations and 
Mexican government's higher taxes both negatively impacted this venture between FAW and Grupo Salinas, but this level of detail escapes inclusion in the RI.

The RI was 1.53 and uses six factors from WGI to analyze the host country government, as seen in Table 2 below. The numbers in Table 2 are converted numbers for use in the RI. The range for these numbers is 0 to 7, with a mid-point of 3.5. The range is interpreted thus: the higher the number the poorer the quality, thus the lower the number, the higher the quality. For example, a country with a six in Political Stability would be considered very unstable. For Mexico, the categories are mid-range. Political Stability and Absence of Violence is slightly higher than the 3.5 midpoint, which means there is some instability in the government. This factor is not critiqued by Cuervo-Cazurra et al. (2016) and is possibly not considered high enough to be a risk.

Rule of Law is also slightly above the mid-point and may be interpreted as the enforcement of laws such as contracts, court decisions, and the police. Control of Corruption is also above 3.5, which may indicate a use of personal power for gain. These three factors: Political Stability and Absence of Violence, Rule of Law, and Control of Corruption, may be indicators of interest since they are above 3.5 and all three may directly involve the governments effect on business, which might explain the tax increases.

The other three factors (Voice and Accountability, Government Effectiveness, and Regulatory Quality) are all lower than 3.5 and would indicate strengths of the government in those areas. Voice and Accountability shows that people have a certain amount of freedom. Government Effectiveness shows the quality of public services. 
Regulatory Quality shows that the government enacts measures to promote improvement within the private sector. From these indicators, firms might chose to be more or less cautious about expansion into certain countries. In the case of Mexico these factors would seem to warrant cautious consideration.

\section{TABLE 2 Mexico WGI}

\begin{tabular}{|c|c|c|c|c|c|c|}
\hline \multirow{3}{*}{ Country } & \multicolumn{6}{|l|}{ Political } \\
\hline & Stability and & & & & & \\
\hline & $\begin{array}{l}\text { Absence of } \\
\text { Violence }\end{array}$ & $\begin{array}{l}\text { Rule of } \\
\text { Law }\end{array}$ & $\begin{array}{l}\text { Voice and } \\
\text { Accountability }\end{array}$ & $\begin{array}{l}\text { Government } \\
\text { Effectiveness }\end{array}$ & $\begin{array}{l}\text { Control of } \\
\text { Corruption }\end{array}$ & $\begin{array}{l}\text { Regulatory } \\
\text { Quality }\end{array}$ \\
\hline MEXICO & 4.237961888 & 4.08191 & 3.349121734 & 3.35436818 & 3.8693812 & 3.2367133 \\
\hline
\end{tabular}

The third area the RI covers is country variables. While Cuervo-Cazurra et al. (2016) mentioned entry mode, as discussed earlier, which is one of the RI country variables, they did not discuss the other country variables considered in the RI. These other variables are geographic distance, days to start a business, and cultural overlap (CO). The joint venture between FAW and Grupo Salinas involved FAW sending cars to Mexico. There is a significant geographic distance between China and Mexico and, from transaction cost economics, transportation costs must be a factor in the decision making of whether to go international or not. It is 12,518 kilometers between China and Mexico. This is nearly half way around the world and it can thus be surmised that transportation costs will be high (Williamson, 1981), thus producing an RI number of 1.62 .

The next variable is days to start a business. The premise here is that the longer it takes to start a business, the less likely a firm is to have a successful venture in that country. The number of days to start a business is based on the fastest legally possible 
way to start a business. To start a business in Mexico using this method is thirty days. This is favorable, given that some countries require 970 days as the fastest legal way to start a business. Therefore, days to start a business should not be a negative factor in the RI for this case which is shown with a RI number of 1.04 .

The last measure is the Cultural Overlap model, as proposed by Maseland (2011). This model uses within country variance to determine to what extent two countries are alike. The belief is that the more two countries have in common, the easier it will be to adapt to the cultural differences. If China and Mexico are culturally similar, then the RI number for CO will be small, conversely if they are culturally different, then the RI number will be high. The RI number generated is between 1 and 2 with one being the most culturally similar and two being the most culturally dissimilar. The RI number for China and Mexico is 1.83, which is very high. This may account for some of the difficulty encountered by FAW trying to enter the Mexican market. Because the CO looks at similarities as reported by the people in each country, it can be seen and is confirmed by Cuervo-Cazurra et al. (2016) in their observation that the Mexican people did not trust Chinese made cars. Joint ventures are entered into in hopes that some of these barriers will be addressed by the host country firm, but it would appear that Grupo Salinas did not factor this cultural difference into the equation and take pro-active measures.

As Cuervo-Cazurra et al. (2016) point out, this seemed to be a good match for both companies at the time they made their agreement. But since this venture did not work out, Cuervo-Cazurra et al. (2016) address what they view as some of the reasons 
why this venture failed. They believe understanding competitive and comparative advantages are first and foremost in understanding success or failure in cross border expansion. Added to this element, and equally as important, is the possibility of transferring these advantages and, if so, how these advantages are transferred. In the case of FAW, their competitive advantages did not transfer to Mexico. Cuervo-Cazurra et al. (2016) point out that there may be a difference between customers at home and customers in the host country. Had they used the RI, the firms would have been aware of the high CO score and possibly taken measures to address this issue. Cuervo-Cazurra et al. (2016) go on to give a checklist of things to consider when going abroad. The RI is a tool that may add to the usefulness of this checklist.

Had the RI been used in this scenario, what would have been the results? Would the venture have been successful? To state that a venture would be successful due to the use of one tool would be erroneous. However, to say that using the RI in conjunction with other measures, such as Cuervo-Cazurra et al.’s (2016) checklist, would better prepare managers for international expansion, would not necessarily be erroneous. Looking at the RI as an aggregate, the number it produces will give an idea of how much resistance will be met when attempting the given endeavor. It is scaled from 1 to 12 so the higher the number the more resistance there will be. The number produced for the FAW venture is 11.01. This would have alerted the participants that this venture was going to be very difficult. In conjunction with Cuervo-Cazurra et al.’s (2016) recommendations, they could have considered the breakdown of the different categories of the RI, as explained earlier, and then considered whether they would be able to make the adjustments 
necessary to reduce this number, or if it would be better to have abandoned the proposed venture.

This venture took place over several years. Since the data in the RI are updated regularly, we can look at what differences might have been made and what the results of those changes may have been in a different time period. Just by moving the date to 2015, the number decreases from 11.01to 9.1. What is the reasoning behind this change? We know that certain factors of the RI will not change, such as geographic distance. But what happens to things such as the ESG? Maybe the firm realizes the need for change and makes a concerted effort to accomplish this change. In Table 3, we can see a comparison of the two different years. In the Corporate Governance area, we see tremendous changes across all sub categories. The lowest ESG score was Board Functions in the earlier time period at 3.52 but in 2015 it is 25.94. The average score for Corporate Governance in 2010 was 16.85, but in 2015 it rose to 45.3. In the Economic category, we can see a marked drop from 37.81 to 21.53 . This could be due to several factors, such as increased competition. The Environmental category had a sharp increase, going from an average of 34.41 to 52.55. This may be due in part to the awareness of the environment caused by movements such as “go green.” It may have also been a result of trying to meet certain environmental standards as imposed by DOT mentioned earlier, a factor that may also account for the drop in the Economic category. The Social category saw the biggest change, with the average sub category score in 2010 being 20.03 and jumping to 60.23 in 2015. While the sub-categories of Diversity and Opportunity and Human Rights remain low, the other five areas show significant gains. Looking at the marked change in ESG is 
an example of how the resistance to a venture can change over time and is shown with the change in RI from 11.01 in 2010 down to 9.1 in 2015.

TABLE 3 Dongfeng Motor ESG 2010-2015

$\begin{array}{lcc}\text { CORPORATE GOVERNANCE } & 2010 & 2015 \\ \text { DONGFENG MOTOR GP.'H' - Board of Directors/Board Functions } & 3.52 & 25.94 \\ \text { DONGFENG MOTOR GP.'H' - Board of Directors/Board Structure } & 11.12 & 66.47 \\ \text { DONGFENG MOTOR GP.'H' - Board of Directors/Compensation Policy } & 45.53 & 60.05 \\ \text { DONGFENG MOTOR GP.'H' - Integration/Vision and Strategy } & 15.28 & 45.88 \\ \text { DONGFENG MOTOR GP.'H' - Shareholders /Shareholder Rights } & 8.82 & 28.14 \\ \text { ECONOMIC } & & \\ \text { DONGFENG MOTOR GP.'H' - Margins /Performance } & 51.87 & 21.44 \\ \text { DONGFENG MOTOR GP.'H' - Profitability /Shareholder Loyalty } & 37.28 & 39.45 \\ \text { DONGFENG MOTOR GP.'H' - Revenue /Client Loyalty } & 24.29 & 3.69 \\ \text { ENVIRONMENTAL } & & \\ \text { DONGFENG MOTOR GP.'H' - Emission Reduction } & 15.28 & 44.23 \\ \text { DONGFENG MOTOR GP.'H' - Product Innovation } & 76.3 & 57.3 \\ \text { DONGFENG MOTOR GP.'H' - Resource Reduction } & 11.66 & 56.13 \\ \text { SOCIAL } & & \\ \text { DONGFENG MOTOR GP.'H' - Customer /Product Responsibility } & 3.84 & 72.17 \\ \text { DONGFENG MOTOR GP.'H' - Society /Community } & 12.93 & 77.51 \\ \text { DONGFENG MOTOR GP.'H' - Society /Human Rights } & 25.6 & 17.6 \\ \text { DONGFENG MOTOR GP.'H' - Workforce /Diversity and Opportunity } & 10.02 & 8.42 \\ \text { DONGFENG MOTOR GP.'H' - Workforce /Employment Quality } & 37.63 & 78.67 \\ \text { DONGFENG MOTOR GP.'H' - Workforce /Health \& Safety } & 28.13 & 93.4 \\ \text { DONGFENG MOTOR GP.'H' - Workforce /Training and Development } & 22.05 & 73.82\end{array}$

The CD is a very popular index used for looking at cross border expansion. It uses Hofstede's cultural dimensions to calculate the distance between cultures. While there are those who criticize the index, (e.g. Shenkar, 2001) the index is still very popular today. The CD produces one number like the RI, but the CD number is based on data collected from the late1960s and early 1970s and is not systematically updated. Thus, the CD remains somewhat constant, unlike the RI. The original CD used four cultural dimensions, which is what is used for this comparison (there is a fifth dimension, but it is 
seldom used). The result of the CD index for our case study looks at the distance between China and Mexico and produces a number of 1.52. Since the CD has a median of 1.61 the results for China and Mexico are below the median, which would support the belief that the venture should not have been extremely difficult. The range of the CD is from 0 to 12.3, further supporting the belief that this undertaking might have been reasonably successful. As Cuervo-Cazurra et al.'s (2016) analysis pointed out, on the surface it seemed like this undertaking should have succeeded.

\section{Case 2}

Vale is one of the three largest iron ore producers in the world. One of its main customers was China. Vale developed and produced large ships to handle a significant load so as to make Vale competitive with its rivals (Cuervo-Cazurra et al., 2016). Looking at this case, it is different from Case 1 in two main categories. First, this case involves exporting instead of joint venture. Second, in Case 1 Dongfeng was used as a substitute for FAW, but in this case there is no need for a substitute since Vale is included in the ESG dataset, but can use data actually representing the firm in question. Case 2, like Case 1, was also considered a failure in that Vale was unable to transfer their advantage to China since the Chinese government passed regulations against the large ships Vale was using. Comparing Vale, Case 2, to FAW, Case 1, is useful since we do not have to rely on an analysis of a substitute (Dongfeng for FAW) to a firm listed in the ESG dataset. The ESG data for Vale (Table 4), is considerably higher than that of FAW shown in Case 1. This should reduce the RI in comparison to FAW (1.29 versus 1.76 
respectively), producing a more favorable result in the RI, indicating greater likelihood of success.

\section{TABLE 4 Vale ESG}

\section{CORPORATE GOVERNANCE}

VALE PN - Board of Directors/Board Functions 19.54

VALE PN - Board of Directors/Board Structure 4.78

VALE PN - Board of Directors/Compensation Policy $\quad 55.09$

VALE PN - Integration/Vision and Strategy $\quad 82.5$

VALE PN - Shareholders /Shareholder Rights 84.69

ECONOMIC

VALE PN - Margins /Performance $\quad 90.92$

VALE PN - Profitability /Shareholder Loyalty $\quad 93.83$

VALE PN - Revenue /Client Loyalty $\quad 93.49$

ENVIRONMENTAL

VALE PN - Emission Reduction $\quad 86.65$

VALE PN - Product Innovation $\quad 78.4$

VALE PN - Resource Reduction $\quad 89.04$

SOCIAL

VALE PN - Customer/Product Responsibility $\quad 80.29$

VALE PN - Society /Community $\quad 66.52$

VALE PN - Society /Human Rights $\quad 75.79$

VALE PN - Workforce /Diversity and Opportunity $\quad 84.59$

VALE PN - Workforce /Employment Quality $\quad 91.23$

VALE PN - Workforce /Health \& Safety $\quad 94.68$

VALE PN - Workforce /Training and Development $\quad 89.94$

However, government factors played a role in the problems encountered in each case. Looking at the WGI for the Vale case involves China as the host country. The data in Table 5 show that China has higher numbers than Mexico, Table 2. Any number greater than 3.5 is considered to be high and care should be considered with ventures into these countries. China has above 4 in all categories while Mexico had only two categories above 4, one above 3.5, and three below 3.5. Mexico, by these numbers, has less risk governmentally than China. Therefore, a venture into China should consider the 
government as being a high risk as was demonstrated by the RI numbers of 1.53 for Mexico and 1.58 for China in the Vale case.

\section{TABLE 5 China WGI}

\begin{tabular}{llcllll}
\multirow{2}{*}{ Country } & $\begin{array}{l}\text { Political } \\
\text { Stability and }\end{array}$ & & & & \\
& Absence of & & Voice and & Government & Control of & Regulatory \\
& Violence & Rule of Law & Accountability & Effectiveness & Corruption & Quality \\
CHINA & 4.156603992 & 4.105860114 & 4.052419662 & 4.046183765 & 4.034429967 & 4.06054902
\end{tabular}

The country factor, Days to Start a Business, was very similar for both countries with Mexico taking thirty days to start a business and China taking 22 days (RI 1.04 versus 1.02). The Geographic Distance variable for Brazil to China (16,911 kilometers) was greater than Mexico to China (12,518 kilometers), which impacted on the RI going from 1.62 to 1.84 . The Entry Mode would normally be less of a barrier on the RI for Vale since they are exporting, whereas FAW involved a joint venture. But this is not the case (RI 1.32 joint venture to 1.4 exporting) and may show the reluctance of China to imports. This could have been a signal to Vale that this may not be as simple a transaction as originally thought. The Cultural Overlap variable is almost the same for both scenarios with the Vale case being 1.82 and the FAW case being 1.83. As pointed out in the first case, a number this high means a high degree of difficulty for the success of a venture from a cultural standpoint.

The number produced by the RI for the Vale case is 9.46 and anything above 6.5 is considered to be difficult to succeed. The reason for the Vale difficulty turned out to be the government which was shown to be a concern in the RI. That factor, coupled with a 
high degree of difference between cultures, was an important reason for Vale's problems. The RI produced numbers in both Case 1 and Case 2 were above 6.5, and both cases were deemed failures. The RI was also able to show the areas of concern that were shown to be problem areas in the analysis by Cuervo-Cazurra et al., (2016).

How does the RI compare to the CD in this second case? Once again, the CD measure needs to be considered given its widespread appeal. As mentioned before, the median number for the $\mathrm{CD}$ is1.61. The CD number for Brazil to China is also 1.61. It would appear that the $\mathrm{CD}$ would be neutral in this venture while the RI would be predicting a difficulty with this venture. Therefore, it would appear that the RI would provide a helpful suppliment to the CD in both Case 1 and Case 2. Also, the RI can be a useful tool when used in conjunction with the Cuervo-Cazurra et al., (2016) recommendations.

\section{Case 3}

The third case involves Cemex, a Mexican corporation that is the world's third largest cement producer. Cemex is heavily involved in international expansion and has a proprietary method of incorporating other businesses into Cemex. Cemex also has had training programs in place for managers and employees to address the incorporation of other companies into Cemex (Cuervo-Cazurra et al., 2016). In this third case, the expansion of Cemex into Colombia via acquisition, has many aspects that differ from the first two cases as we shall see in the analysis that follows.

The most notable difference between Cemex and the first two cases is that this case was a success although it did have difficulties. As before, the ESG is the first place to start and, 
as expected, the numbers are very good for Cemex (Table 6). There are areas that could be improved, as with any company, such as Board Structure, Board Functions, and Profitability/Shareholder Loyalty. However, overall Cemex looks to have a very good firm for international expansion with an RI of 1.26. As Cuervo-Cazurra et al. (2016) point out, Cemex has “mastered the art of acquisition and integration” (p. 56). Therefore we would expect the firm variable for RI to add very little to the resistance of international expansion undertaken by Cemex.

\section{TABLE 6 Cemex ESG}

$\begin{array}{lr}\text { CORPORATE GOVERNANCE } & \\ \text { CEMEX CPO - Board of Directors/Board Functions } & 24.47 \\ \text { CEMEX CPO - Board of Directors/Board Structure } & 5.35 \\ \text { CEMEX CPO - Board of Directors/Compensation Policy } & 56.86 \\ \text { CEMEX CPO - Integration/Vision and Strategy } & 93.25 \\ \text { CEMEX CPO - Shareholders /Shareholder Rights } & 60.65 \\ \text { ECONOMIC } & \\ \text { CEMEX CPO - Margins /Performance } & 95.09 \\ \text { CEMEX CPO - Profitability /Shareholder Loyalty } & 26.41 \\ \text { CEMEX CPO - Revenue /Client Loyalty } & 95.8 \\ \text { ENVIRONMENTAL } & \\ \text { CEMEX CPO - Emission Reduction } & 87.55 \\ \text { CEMEX CPO - Product Innovation } & 94.81 \\ \text { CEMEX CPO - Resource Reduction } & 86.71 \\ \text { SOCIAL } & \\ \text { CEMEX CPO - Customer /Product Responsibility } & 95.99 \\ \text { CEMEX CPO - Society /Community } & 94.37 \\ \text { CEMEX CPO - Society /Human Rights } & 93.76 \\ \text { CEMEX CPO - Workforce /Diversity and Opportunity } & 94.9 \\ \text { CEMEX CPO - Workforce /Employment Quality } & 95.93 \\ \text { CEMEX CPO - Workforce /Health \& Safety } & 50.44 \\ \text { CEMEX CPO - Workforce /Training and Development } & 84.18\end{array}$


Governmental factors were important in the first two cases, having a direct bearing on the difficulties encountered by both FAW (RI 1.53) and VALE (RI 1.58). A look at the governmental factors for the RI (1.54) reveals a similar situation in Colombia (Table 7). As with Mexico, Colombia has all factors scoring mid-level. As we can see in Table 7, all areas are around 3.5 except Political Stability and Absence of Violence which is above 4.5, a number higher than any of the other countries. This should have alerted Cemex to a potential problem area, enabling managers to develop back up plans in case of governmental turmoil.

TABLE 7 Colombia WGI

\begin{tabular}{clclccc}
\multicolumn{1}{c}{ Country } & $\begin{array}{l}\text { Political } \\
\text { Stability and } \\
\text { Absence of }\end{array}$ & & & & & \\
& $\begin{array}{l}\text { Voice and } \\
\text { Violence }\end{array}$ & Rule of Law & Accountability & $\begin{array}{l}\text { Government } \\
\text { Effectiveness }\end{array}$ & $\begin{array}{c}\text { Control of } \\
\text { Corruption }\end{array}$ & $\begin{array}{c}\text { Regulatory } \\
\text { Quality }\end{array}$ \\
COLOMBIA & 4.784212 & 3.94104 & 3.610863 & 3.425129 & 3.930266 & 3.093387
\end{tabular}

The country factors are also different in this case than what was shown in the first two cases. As noted before, Cemex expands into Colombia via acquisition. An acquisition is the most difficult expansion method compared to exporting (VALE), or joint venture (FAW) and should add to the RI. But again we see a difference with the RI being only 1.3 which may signal Colombia’s desire to attract foreign investors. The Geographic Distance is 3169 kilometers which is considerably less than case 1 or case 2 . This should have very little bearing on the RI (1.01) since the closer the proximity of the host country the less cost involved with conducting business between the home and host countries. The $\mathrm{CO}$ is very similar to both previous cases at 1.8 in the RI. This number would seem to be incorrect because most evaluations only look at both countries being 
Hispanic and close geograpically. The CO goes deeper into the values held in common between two countries and that is why two Hispanic countries can still be distant culturally.

The final result of the RI is 5.4, below the mid-point of 6.5 meaning this venture should be successful. Due to this number's being on the high side of the range indicating likely success, a manager should still take precautions with this venture. As noted before, a backup plan may be needed in case of government problems and cultural differences exist in spite of both countries being Hispanic. Cemex has very good firm numbers, and this element, along with the close proximity of Colombia, should offset the adverse conditions identified, therefore a successful RI number was produced even though areas of vulnerability were identified. The CD number, 0.29 , would indicate a very easy and therefore successful venture for Cemex. But, as pointed out by Cuervo-Cazurra et al. (2016) this was not the case. As Cuervo-Cazurra et al. (2016) state "systems used in Mexico on the newly acquired Colombian firm resulted in an exodus of local talent” (p. 57). This may have been caused by the cultural differences pointed out in the RI that suggested this would not be an easy expansion for Cemex.

\section{Conclusion}

The RI is a tool for helping to understand the complexity of international expansion. No one tool is capable of explaining everything involved with international expansion and the RI is not meant to be such a tool. But in combination with other tools it may add to the understanding of the researcher or practitioner. 
In case 1, the RI supplemented the checklist of Cuervo-Cazurra et al. (2016) by adding a more in-depth analysis. This was achieved by looking into the firm FAW using the data of a substitute company, Dongfeng, and realizing the firm had several areas of concern for international expansion. The government of Mexico was not of great concern with favorable numbers in the RI. The geographic distance was shown to be a concern by the RI and this analysis was backed up by relevant information from Williamson (1981). The cultural differences were shown to be of concern in the RI and were possibly the reason for Salinas not doing more to insure the success of the venture. The RI revealed a very high number in this scenario, meaning this was a venture with very high resistance. Note that when the CD index considered, it produced a number that showed this venture should have been easy. Cuervo-Cazurra et al. (2016) point out several reasons for this venture failing consistent with the details provided by the RI analysis.

In case 2, a similar case, the RI once again shows high resistance to the venture, and indeed the Vale expansion into China was considered a failure as discussed previously. Cuervo-Cazurra et al. (2016) talk about three possible reasons why firms have difficulty transferring advantages abroad and the RI, once again, was able to add to this conversation. The government factor in RI was high, and the Chinese government was instrumental in the failure of this venture. The cultural factor also showed a notable difference in the two countries and may have played a role in the government's decisions. The CD was also looked at in this scenario and produced a mid-point number that could be interpreted as being neutral. However, the RI number was high, correctly showing the 
difficulty of the venture. Along with the insights from Cuervo-Cazurra et al. (2016), the RI was able to give additional insight to the analysis.

In the final case, case 3, Cemex completed a successful venture into Colombia. This scenario was different from the two other cases, not only in the aspect of success and failure, but because it also showed how certain areas of strength can compensate for areas of weakness. This was shown in the RI with a low resistance number that could be interpreted as possible success with caution.

The CD showed that this third venture should have been easy with a very low distance number. But Cuervo-Cazurra et al. (2016) point out that there were difficulties that Cemex had to overcome in order to be successful in Colombia. This analysis by Cuervo-Cazurra et al. (2016), along with the information from the RI, render a very reasonable picture of the Cemex success in Colombia.

It is also evident that the RI has certain shortcomings. Cuervo-Cazurra et al. (2016) refer to taxes and similarly specific conditions imposed by governments that the $\mathrm{RI}$ is not capable of handling. The RI looks at a more comprehensive picture by including the three areas of firm, country, and government. That is why the RI is considered a supplemental tool to be used with other tools such as the Cuervo-Cazurra et al. (2016) checklist. When compared to the CD, the RI would seem to add more to the analysis. In the first case the CD was incorrect in predicting likely success, while the RI correctly predicted failure. In the second case CD was neutral in its prediction, while RI correctly predicted failure. In the third case CD predicted success, while RI more accurately predicted success with difficulty. This level of detail provided by the RI allows managers 
to anticipate likely areas of difficulty in international expansion. The RI's ability to predict success and failure in these cases would seem to add more to the analysis of cross border expansion than the CD. Therefore, we see strong evidence that the RI can be a useful tool when considering international expansion.

\section{REFERENCES}

Ahammad, M. F., \& Glaister, K. W. (2011). Postacquisition management and performance of cross-border acquisitions. International Studies of Management \& Organization, 41(3), 59-75.

Ahammad, M. F., Tarba, S. Y., Liu, Y., \& Glaister, K. W. (2016). Knowledge transfer and cross-border acquisition performance: The impact of cultural distance and employee retention. International Business Review, 25(1), 66-75.

Almeida, P., \& Kogut, B. (1999). Localization of knowledge and the mobility of engineers in regional networks. Management science, 45(7), 905-917.

Ambos, B., \& Håkanson, L. (2014). The concept of distance in international management research. Journal of International Management, 20(1), 1-7.

Apud, S., Lenartowicz, T., \& Johnson, J. P. (2003). Intercultural competence: what do practitioners really know? In Proceedings, Academy of International Business SouthEast Region Conference, Clearwater.

Au, K. Y. (2000). Intra-cultural variation as another construct of international management: A study based on secondary data of 42 countries. Journal of international management, 6(3), 217-238.

Avallone, E. A., Baumeister, T., Sadegh, A., \& Marks, L. S. (2007). Friction. Marks' Standard Handbook for Mechanical Engineers, McGraw Hill, New York.

Axelrod, R. (1997). The dissemination of culture a model with local convergence and global polarization. Journal of conflict resolution, 41(2), 203-226.

Aybar, B., \& Ficici, A. (2009). Cross-border acquisitions and firm value: An analysis of emerging-market multinationals. Journal of International Business Studies, 40(8), 13171338. 
Azman-Saini, W. N. W., Law, S. H., \& Ahmad, A. H. (2010). FDI and economic growth: New evidence on the role of financial markets. Economics letters, 107(2), 211213.

Bae, J. H., \& Salomon, R. (2010). Institutional distance in international business research. In The past, present and future of international business \& management (pp. 327-349). Emerald Group Publishing Limited.

Bandyopadhyay, S., Roy, S., \& Liu, Y. (2015). Contract Enforcement, Corruption Controls and Other Institutions Affect Trade, Too. The Regional Economist, (April).

Bartlett, C. A., \& Ghoshal, S. (1989). Managing across borders: The transnational solution. Harvard Business Press.

Benito, G. R., \& Gripsrud, G. (1992). The expansion of foreign direct investments: discrete rational location choices or a cultural learning process? Journal of International Business Studies, 23(3), 461-476.

Berry, H., Guillén, M. F., \& Zhou, N. (2010). An institutional approach to cross-national distance. Journal of International Business Studies, 41(9), 1460-1480.

Beugelsdijk, S., Maseland, R., \& Hoorn, A. (2015). Are scores on Hofstede's dimensions of national culture stable over time? A cohort analysis. Global Strategy Journal, 5(3), 223-240.

Beugelsdijk, S., \& Maseland, R. (2010). Culture in economics: History, methodological reflections and contemporary applications. Cambridge University Press.

Black, J. S., Mendenhall, M., \& Oddou, G. (1991). Toward a comprehensive model of international adjustment: An integration of multiple theoretical perspectives. Academy of management review, 16(2), 291-317.

Bove, V., \& Gokmen, G. (2016). Cultural distance and interstate conflicts. British Journal of Political Science, 1-11.

Branstetter, L. G. (2001). Are knowledge spillovers international or intranational in scope?: Microeconometric evidence from the US and Japan. Journal of International Economics, 53(1), 53-79.

Brewster, C. (1995). Effective expatriate training. Expatriate management: New ideas for international business, 57-71.

Brewer, P. A. (2007). Operationalizing psychic distance: A revised approach. Journal of International Marketing, 15(1), 44-66. 
Brouthers, K. D., \& Brouthers, L. E. (2000). Acquisition or greenfield start-up? Institutional, cultural and transaction cost influences. Strategic Management Journal, 8997.

Brown, L. T., Rugman, A. M., \& Verbeke, A. (1989). Japanese joint ventures with western multinationals: Synthesising the economic and cultural explanations of failure. Asia Pacific Journal of Management, 6(2), 225-242.

Buckley, P.J. \& M. Casson. 1976. The Futureof the Multinational Enterprise. London: MacMillan.

Buono, A. F., \& Bowditch, J. L. (1989). (1989). Human side of mergers and acquisitions. Managing collisions between people, cultures, and organizations. The. Jossey-Bass Publishers.

Colakoglu, S., \& Caligiuri, P. (2008). Cultural distance, expatriate staffing and subsidiary performance: The case of US subsidiaries of multinational corporations. The international journal of human resource management, 19(2), 223-239.

Cuervo-Cazurra, A., Newburry, W., \& Park, S. H. (2016). Emerging Market Multinationals: Managing Operational Challenges for Sustained International Growth. Cambridge University Press.

Diener, E., \& Suh, E. M. (2000). Culture and subjective well-being. MIT press.

Dikova, D., \& Sahib, P. R. (2013). Is cultural distance a bane or a boon for cross-border acquisition performance?. Journal of World Business, 48(1), 77-86.

Dodd, O., Frijns, B., \& Gilbert, A. (2015). On the Role of Cultural Distance in the Decision to Cross-List. European Financial Management, 21(4), 706-741.

Doremus, L., Harbuziuk, W. L., \& Blaha, D. L. (1998). U.S. Patent No. 5,815,565. Washington, DC: U.S. Patent and Trademark Office.

Dow, D. (2000). A note on psychological distance and export market selection. Journal of International Marketing, 8(1), 51-64.

Dow, D., \& Karunaratna, A. (2006). Developing a multidimensional instrument to measure psychic distance stimuli. Journal of international business studies, 37(5), 578602.

Drogendijk, R., \& Zander, L. (2010). Walking the cultural distance: In search of direction beyond friction. In The past, present and future of international business \& management (pp. 189-212). Emerald Group Publishing Limited. 
Elsass, P. M., \& Veiga, J. F. (1994). Acculturation in acquired organizations: A forcefield perspective. Human Relations, 47(4), 431-453.

Evans, J., \& Mavondo, F. T. (2002). Psychic distance and organizational performance: An empirical examination of international retailing operations. Journal of international business studies, 33(3), 515-532.

Evans, J., Treadgold, A., \& Mavondo, F. T. (2000). Psychic distance and the performance of international retailers-a suggested theoretical framework. International Marketing Review, 17(4/5), 373-391.

Franke, G. R., \& Richey Jr, R. G. (2010). Improving generalizations from multi-country comparisons in international business research. Journal of International Business Studies, 41(8), 1275-1293.

Gatignon, H., \& Anderson, E. (1988). The multinational corporation's degree of control over foreign subsidiaries: An empirical test of a transaction cost explanation. Journal of Law, Economics, \& Organization, 4(2), 305-336.

Gomes, E., Angwin, D. N., Weber, Y., \& Yedidia Tarba, S. (2013). Critical success factors through the mergers and acquisitions process: revealing pre-and post-M\&A connections for improved performance. Thunderbird international business review, 55(1), 13-35.

Gomes, E., Weber, Y., Brown, C., \& Tarba, S. Y. (2011). Mergers, acquisitions and strategic alliances: Understanding the process. Palgrave Macmillan.

Goodnow, J. D., \& Hansz, J. E. (1972). Environmental determinants of overseas market entry strategies. Journal of International Business Studies, 33-50.

Håkanson, L., \& Ambos, B. (2010). The antecedents of psychic distance. Journal of International Management, 16(3), 195-210.

Harzing, A. W., \& Christensen, C. (2004). Expatriate failure: time to abandon the concept?. Career

Development International, 9(7), 616-626.

Hammond, J. S., Keeney, R. L., \& Raiffa, H. (1998). The hidden traps in decision making. Harvard business review, 76(5), 47-58

Harzing, A. W. (2000). An empirical analysis and extension of the Bartlett and Ghoshal typology of multinational companies. Journal of international business studies, 31(1), 101-120. 
Harzing, A. W., \& Pudelko, M. (2016). Do we need to distance ourselves from the distance concept? Why home and host country context might matter more than (cultural) distance. Management International Review, 56(1), 1-34.

Hofstede, G. (1980). Motivation, leadership, and organization: do American theories apply abroad?. Organizational dynamics, 9(1), 42-63.

Hofstede, G., Neuijen, B., Ohayv, D. D., \& Sanders, G. (1990). Measuring organizational cultures: A qualitative and quantitative study across twenty cases. Administrative science quarterly, 286-316.

Holzmüller, H. H., \& Kasper, H. (1991). On a theory of export performance: Personal and organizational determinants of export trade activities observed in small and mediumsized firms. MIR: Management International Review, 45-70.

Housel, T., \& Nelson, S. (2004). Knowledge Valuation and Portfolio Management for Capabilities-Based Planning. Office of Force Transformation, Department of Defense, Washington, DC.

Johanson, J., \& Vahlne, J. E. (1977). The internationalization process of the firm-a model of knowledge development and increasing foreign market commitments. Journal of international business studies, 8(1), 23-32.

Johnson, J. P., Lenartowicz, T., \& Apud, S. (2006). Cross-cultural competence in international business: Toward a definition and a model. Journal of International Business Studies, 37(4), 525-543.

Keller, W. (2002). Geographic localization of international technology diffusion. The American Economic Review, 92(1), 120-142.

Kirkman, B. L., Lowe, K. B., \& Gibson, C. B. (2006). A quarter century of culture's consequences: A review of empirical research incorporating Hofstede's cultural values framework. Journal of international business studies, 37(3), 285-320.

Kogut, B., \& Singh, H. (1988). The effect of national culture on the choice of entry mode. Journal of international business studies, 19(3), 411-432.

Kwon, Y. C., \& Konopa, L. J. (1993). Impact of host country market characteristics on the choice of foreign market entry mode. International Marketing Review, 10(2).

Laurent, A. (1986). The cross-cultural puzzle of international human resource management. Human resource management, 25(1), 91-102.

Leung, K., \& Peterson, M. F. (2011). Managing a globally distributed workforce: Social and interpersonal issues. 
Luo, Y. (2004). A coopetition perspective of MNC-host government relations. Journal of International Management, 10(4), 431-451.

Luo, Y., \& Shenkar, O. (2011). Toward a perspective of cultural friction in international business. Journal of International Management, 17(1), 1-14.

Maseland, R. (2011). Cultural overlap and MNE location decisions. In Nagoya: Paper presented at the Academy of International Business Annual Meeting.

Miller, S. R., \& Eden, L. (2006). Local density and foreign subsidiary performance. Academy of Management journal, 49(2), 341-355.

Morosini, P., Shane, S., \& Singh, H. (1998). National cultural distance and cross-border acquisition performance. Journal of international business studies, 29(1), 137-158.

Nebus, J., \& Chai, K. H. (2014). Putting the "psychic" back in psychic distance: Awareness, perceptions, and understanding as dimensions of psychic distance. Journal of International Management, 20(1), 8-24.

Nielsen, B. B., \& Nielsen, S. (2013). Top management team nationality diversity and firm performance: A multilevel study. Strategic Management Journal, 34(3), 373-382.

Nordstrom, K., \& Vahlne, J. E. (1994). Is the Globe Shrinking? PsychicDistance and the Establishment ofSwedish Sales Subsidiaries During theLast 100 Years. International Trade: Regional andGlobal Issues. United Sates: St. Martin's PressNordstromIs the Globe Shrinking.

Nunn, N. (2007). Relationship-specificity, incomplete contracts, and the pattern of trade. The Quarterly Journal of Economics, 122(2), 569-600.

O'Grady, S., \& Lane, H. W. (1996). The psychic distance paradox. Journal of international business studies, 27(2), 309-333.

Padmanabhan, P., \& Cho, K. R. (1996). Ownership strategy for a foreign affiliate: An empirical investigation of Japanese firms. MIR: Management International Review, 4565.

Park, S. H., \& Ungson, G. R. (1997). The effect of national culture, organizational complementarity, and economic motivation on joint venture dissolution. Academy of Management journal, 40(2), 279-307.

Popli, M., \& Kumar, V. (2015). Jumping from springboard? The role of marginal cultural distance in cross-border M\&A deal completion. Thunderbird International Business Review. 
Rao, A. N., Pearce, J. L., \& Xin, K. (2005). Governments, reciprocal exchange and trust among business associates. Journal of International Business Studies, 36(1), 104-118.

Reus, T. H., \& Lamont, B. T. (2009). The double-edged sword of cultural distance in international acquisitions. Journal of International Business Studies, 40(8), 1298-1316.

Ricks, F., \& Vanier Institute of the Family. (1999). All together now: Creating a social capital mosaic. Frances Ricks.

Rugman, A. M., \& Verbeke, A. (2008). A new perspective on the regional and global strategies of multinational services firms. Management International Review, 48(4), 397411.

Salomon, R., \& Wu, Z. (2012). Institutional distance and local isomorphism strategy. Journal of International Business Studies, 43(4), 343-367.

Sarala, R. M., \& Vaara, E. (2010). Cultural differences, convergence, and crossvergence as explanations of knowledge transfer in international acquisitions. Journal of International Business Studies, 41(8), 1365-1390.

Sarkissian, S., \& Schill, M. J. (2004). The overseas listing decision: New evidence of proximity preference. Review of Financial Studies, 17(3), 769-809.

Schneider, S. C. (1988). National vs. corporate culture: Implications for human resource management. Human resource management, 27(2), 231-246.

Schwarz, N. (1994). Judgment in a social context: Biases, shortcomings, and the logic of conversation. Advances in experimental social psychology, 26, 123-162.

Shenkar, O. (2001). Cultural distance revisited: Towards a more rigorous conceptualization and measurement of cultural differences. Journal of international business studies, 32(3), 519-535.

Shenkar, O. (2012). Beyond cultural distance: Switching to a friction lens in the study of cultural differences. Journal of International Business Studies, 43(1), 12-17.

Shenkar, O., Luo, Y., \& Yeheskel, O. (2008). From “distance” to “friction”: Substituting metaphors and redirecting intercultural research. Academy of Management Review, 33(4), 905-923.

Siegel, J. I., Licht, A. N., \& Schwartz, S. H. (2013). Egalitarianism, cultural distance, and foreign direct investment: A new approach. Organization Science, 24(4), 1174-1194. 
Slangen, A. H. (2006). National cultural distance and initial foreign acquisition performance: The moderating effect of integration. Journal of World Business, 41(2), $161-170$.

Smith, B. (2010). Software, distance, friction, and more: A review of lessons and losses in the debate for a better metaphor on culture. In The Past, Present and Future of International Business \& Management (pp. 213-229). Emerald Group Publishing Limited.

Sousa, C. M., \& Bradley, F. (2006). Cultural distance and psychic distance: two peas in a pod? Journal of International Marketing, 14(1), 49-70.

Storper, M., \& Venables, A. J. (2004). Buzz: face-to-face contact and the urban economy. Journal of economic geography, 4(4), 351-370.

Stöttinger, B., \& Schlegelmilch, B. B. (1998). Explaining export development through psychic distance: enlightening or elusive? International Marketing Review, 15(5), 357372.

Stöttinger, B., \& Schlegelmilch, B. B. (2000). Psychic distance: a concept past its due date? International Marketing Review, 17(2), 169-173.

Taras, V., Steel, P., \& Kirkman, B. L. (2016). Does country equate with culture? Beyond geography in the search for cultural boundaries. Management International Review, 56(4), 455-487.

Taras, V., Steel, P., \& Kirkman, B. L. (2012). Improving national cultural indices using a longitudinal meta-analysis of Hofstede's dimensions. Journal of World Business, 47(3), 329-341.

Teerikangas, S., \& Very, P. (2006). The culture-performance relationship in M\&A: From yes/no to how. British Journal of Management, 17(S1), S31-S48.

Tihanyi, L., Griffith, D. A., \& Russell, C. J. (2005). The effect of cultural distance on entry mode choice, international diversification, and MNE performance: A metaanalysis. Journal of International Business Studies, 36(3), 270-283.

Thomson Reuters. (2017) Asset 4 Environmental, Social, and Governance Report. Retrieved from

http://www.trcri.com/index.php?page=indexdata

Thunell, L. H. (1977). Political risks in international business: Investment behavior of multinational corporations (Vol. 5). Praeger publishers. 
Tung, R. L. (1982). Selection and training procedures of US, European, and Japanese multinationals. California Management Review, 25(1), 57-71.

Tung, R. L., \& Verbeke, A. (2010). Beyond Hofstede and GLOBE: Improving the quality of cross-cultural research. Journal of International Business Studies, 41(8), 12591274.

Vaara, E., Sarala, R., Stahl, G. K., \& Björkman, I. (2012). The impact of organizational and national cultural differences on social conflict and knowledge transfer in international acquisitions. Journal of Management Studies, 49(1), 1-27.

Very, P., Lubatkin, M., \& Calori, R. (1996). A cross-national assessment of acculturative stress in recent European mergers. International Studies of Management \& Organization, 26(1), 59-86.

Von Glinow, M. A., Shapiro, D. L., \& Brett, J. M. (2004). Can we talk, and should we? Managing emotional conflict in multicultural teams. Academy of Management review, 29(4), 578-592.

Weber, Y., \& Tarba, S. (2011). Exploring integration approach in related mergers: Postmerger integration in the high-tech industry. International Journal of Organizational Analysis, 19(3), 202-221.

Weber, Y., Tarba, S. Y., \& Reichel, A. (2011). A model of the influence of culture on integration approaches and international mergers and acquisitions performance. International Studies of Management \& Organization, 41(3), 9-24.

Weber, Y., Yedidia Tarba, S., \& Reichel, A. (2009). International mergers and acquisitions performance revisited-the role of cultural distance and post. In Advances in mergers and acquisitions (pp. 1-17). Emerald Group Publishing Limited.

Weber, Y., Tarba, S. Y., Stahl, G. K., \& Bachar-Rozen, Z. (2012). Integration of international mergers and acquisitions: Test of a new paradigm. Handbook of research on mergers and acquisitions, 32-57.

Williamson, O. E. (1981). The modern corporation: origins, evolution, attributes. Journal of economic literature, 19(4), 1537-1568.

Witt, M. A., \& Redding, G. (2009). Culture, meaning, and institutions: Executive rationale in Germany and Japan. Journal of International Business Studies, 40(5), 859885.

World Bank. (2017). Ease of Doing Business Index. Retrieved from http://data.worldbank.org/indicator/IC.BUS.EASE.XQ 
World Bank. (2017). Time Required to Start a Business. Retrieved from http://data.worldbank.org/indicator/IC.REG.DURS

World Bank. (2017). World Governance Indicators. Retrieved from http://info.worldbank.org/governance/wgi/\#reports

World Bank. (2017). World Development Indicators. Retrieved from http://data.worldbank.org/data-catalog/world-development-indicators

World Values Survey. (2017). World Values Survey Report. Retrieved from http://www.worldvaluessurvey.org/WVSContents.jsp

Zaheer, S. (1995). Overcoming the liability of foreignness. Academy of Management journal, 38(2), 341-363.

Zaheer, S., \& Mosakowski, E. (1997). The dynamics of the liability of foreignness: A global study of survival in financial services. Strategic management journal, 439-463.

Zaheer, S., Schomaker, M. S., \& Nachum, L. (2012). Distance without direction: Restoring credibility to a much-loved construct. Journal of International Business Studies, 43(1), 18-27. 
VITA

\section{DALE ALAN DEJONG}

Born, Platte, South Dakota

1980-1982

B.A., Sociology

University California Los Angeles

Los Angeles, California

1982-2003

Market Maker

Chicago Board Options Exchange

Chicago, Illinois

2009-2010

M.B.A., Finance/International Business

Palm Beach Atlantic University

Palm Beach, Florida

2016-2017

Doctoral Candidate

Florida International University

Miami, Florida

\section{PUBLICATIONS AND PRESENTATIONS}

DeJong, D. A., Zhao, Y., \& Wenger, L. (June, 2015). Government Specific Advantage (GSA): An Extension of Ownership Advantages. Paper presented at the Academy of International Business Conference, Bangalore, India.

DeJong, D. A., Paul, K., Lopez, E., Oramas, L. (April, 2017). Does

Country Specific Advantage (CSA) include Government, or Are They Different Things? A Proposal for Government Specific Advantage (GSA) and Its Application to the Cuba Case. Paper presented at the meeting of the American Marketing Association, Havana, Cuba. 